\title{
A Systematic Review of Insulin Adherence Measures in Patients with Diabetes
}

\author{
Samuel Stolpe, PharmD; Michel A. Kroes, MSc; Neil Webb, BSc Hons; and Tami Wisniewski, MPH
}

\begin{abstract}
BACKGROUND: Diabetes care is associated with a considerable burden to the health care system in the United States, and measuring the quality of health care is an important development goal of the Department of Health and Human Services and the Centers for Medicare \& Medicaid Services. Diabetes is a priority disease within the National Quality Strategy and should therefore remain a focus in the measurement of health care quality. Despite the importance of measuring quality in diabetes care management, no quality measure is currently associated with adherence to insulin treatment, and measuring adherence to insulin is known to be complicated.
\end{abstract}

OBJECTIVES: To (a) identify methods to measure insulin adherence in patients with diabetes and (b) evaluate whether identified methods could be considered for testing as a quality measure.

METHODS: Systematic searches were conducted in the online electronic databases Embase, MEDLINE, and the Cochrane Library, supplemented with additional manual searches to identify publications on insulin adherence from the year 2000 onward. Identified citations were screened for relevance against predefined eligibility criteria, and methods to measure adherence to insulin were extracted from relevant studies into data extraction tables. Methods were critiqued on the feasibility for consideration as a quality measure.

RESULTS: Seventy-eight publications met the inclusion criteria and were reviewed. Included studies reported various indirect methods to measure adherence to insulin, using prescription claims or self-report questionnaires. Commonly reported methods included the (adjusted) medication possession ratio, proportion of days covered, persistence, daily average consumption, and the Morisky Medication Adherence Scale. All types of identified methods were associated with measuring challenges varying from accuracy of estimated adherence, complexity of data collection, absence of validated threshold for good adherence, and reliability of adherence outcomes.

CONCLUSIONS: Without additional research, none of the identified methods are appropriate for use as a quality measure for insulin adherence. We suggest patient involvement in future research and additional quality measure development.

J Manag Care Spec Pharm. 2016;22(11):1224-46

Copyright $\odot 2016$, Academy of Managed Care Pharmacy. All rights reserved.

\section{What is already known about this subject}

A considerable proportion of patients with diabetes use insulin, particularly those with advanced disease.

Good adherence to insulin treatment as prescribed is important in managing diabetes; however, it is difficult to measure adherence levels to injectable medication.
Quality of care delivered is a key aspect of current U.S. health care reform plans and diabetes is considered a priority disease, with metrics being developed to measure the quality of health care delivered.

\section{What this study adds}

This article provides an overview and critique of methods used to measure adherence to insulin in the context of development of quality measures in the United States.

While there is some potential based on previously developed methods to measure insulin adherence, without additional research, none of the identified methods are currently appropriate for use as a quality measure for insulin adherence.

$\square$ iabetes is a chronic metabolic disorder characterized by elevated blood glucose levels (hyperglycemia) and is associated with considerable morbidity and mortality. Type 1 diabetes mellitus (T1DM) is an autoimmune disease in which there is failure by pancreatic islet $\beta$-cells to produce insulin. The American Diabetes Association recommends that T1DM be treated with multiple-dose insulin injections (3 to 4 injections per day of basal and bolus insulin), or continuous subcutaneous insulin infusion. ${ }^{1}$ Type 2 diabetes mellitus (T2DM) is characterized by insulin resistance with progressive loss of $\beta$-cell function and subsequent insulin deficiency. Risk factors for T2DM include obesity, diet, sedentary living, family history of diabetes, and race/ethnicity, to name a few. T2DM is a progressive disease and treatment is intensified with disease progression. Many patients with T2DM will eventually require insulin to control their blood glucose levels, and many patients will need to intensify their treatment regimens over time. ${ }^{2}$

Treatment adherence is critical to effective management of T1DM and T2DM. Adherence to insulin treatment has been associated with improved levels of glycemic control, ${ }^{3}$ which reduces the risk of developing micro- and macro-vascular complications ${ }^{4}$ and all-cause mortality. ${ }^{5}$ However, poor adherence to insulin regimens is common in people with diabetes. ${ }^{6}$ The 2 most commonly reported difficulties with insulin treatment, as reported by both patients and physicians, are the requirements for multiple injections and adherence to prescribed dosing times. ${ }^{7}$ Fear of hypoglycemia, ${ }^{8,9}$ weight gain, ${ }^{9,10}$ and treatment complexity ${ }^{6-9}$ are additional barriers to good adherence to 
insulin treatment. In 2010, Cooke et al. reported that persistence with injectable insulin 12 months after initiation was as low as $28.7 \%$ in a U.S. population of patients with T2DM. ${ }^{11}$

With an estimated prevalence of $14.3 \%$ in 2011-2012, diabetes costs the United States approximately $\$ 245$ billion annually. ${ }^{12}$ The combination of high prevalence and cost of diabetes has resulted in increased attention to appropriate care and control of patients with diabetes among both public and private payers. This increased attention has manifested in the development and implementation of several quality measures intended to ensure adequate disease control at the population level. Table 1 describes current diabetes quality control measures endorsed by the National Quality Forum (NQF). A Pharmacy Quality Alliance (PQA) measure that addresses adherence to diabetes medications is currently being used within the Centers for Medicare \& Medicaid Services (CMS) Star Ratings for Medicare Parts C and D and in the Health Insurance Exchanges Quality Rating System. Through a consensus-based process, $\mathrm{PQA}$ endorsed the proportion of days covered (PDC) method, which is currently considered the measurement standard for adherence to oral medications. ${ }^{13}$

The PQA diabetes medication adherence measure does not include insulin due to feasibility challenges associated with prescription claims data and injectable medication days supply. This is an important challenge to address because approximately $30 \%$ of patients with diabetes, and those with the most advanced disease, are treated with insulin. ${ }^{14}$ Following the passage of the Patient Protection and Affordable Care Act in 2010, which aimed to reduce health care costs while preserving or enhancing the quality of health care delivered, it has become increasing apparent that there is a need for a standardized approach to measure insulin adherence.

Given the known complexity of measuring adherence to injectable treatments and the lack of a quality measure that assesses adherence to insulin in federal quality measurement programs, we conducted a systematic review (SR) to understand the evidence base associated with methods to measure adherence to insulin in patients with diabetes. Our purpose was to identify potential methods that could be considered for further investigation as a quality measure suitable for public-facing performance programs and value-based payment structures.

\section{Methods}

An SR was conducted to identify studies reporting methods to measure adherence to self-injectable treatments in patients with diabetes, rheumatoid arthritis, multiple sclerosis, or human immunodeficiency virus, or in those requiring human growth hormone. Here we present the subset of findings relating to methods of measuring adherence to insulin in patients with diabetes.

\section{Search Methods for Identification of Studies}

The following electronic databases were searched using Ovid: Embase, MEDLINE In-Process \& Other Non-Indexed Citations, MEDLINE, and the Cochrane Library. Only English language publications published from the year 2000 onward were searched.

Search strings are provided in the Appendix (available in online article). The search was run on November 24, 2014, and updated on June 29, 2015. In addition, conference proceedings of interest were searched between 2012 and 2015. Additional supplementary searches included the websites of the NQF database, the Health and Human Services (HHS) Measures Inventory, the Agency for Healthcare Research and Quality National Quality Measures Clearinghouse, and the Health Indicators Warehouse.

\section{Eligibility Criteria}

Key eligibility criteria were recorded a priori in a review protocol (not registered) and are presented in Table 2. Studies were included if participants were adults (aged $\geq 18$ years) with diabetes (type 1 or type 2 , as defined by study, typically by International Classification of Diseases, Ninth Revision, Clinical Modification codes), and measurement of insulin adherence was clearly described. Randomized controlled trials (RCTs) were excluded, as they are protocol driven and may not provide generalizable accurate methods for measuring insulin adherence in the real world for quality reporting purposes.

\section{Data Collection and Analysis}

Citations identified through the searches were assessed by a reviewer (author Webb) based on title and abstract using the predefined eligibility criteria. Full publications of potentially relevant citations were obtained and examined by 2 reviewers (Webb and author Kroes). Disputes were resolved via discussion with third parties (authors Wisniewski and Stolpe). Relevant data from eligible publications were extracted into a data extraction table by a reviewer (Webb) and verified by a second reviewer (Kroes).

Included studies were evaluated for risk of bias using the Newcastle-Ottawa scale (NOS) ${ }^{15}$ : a "star system" to assess the quality of nonrandomized studies on 3 perspectives: selection of study groups; comparability of groups; and ascertainment of exposure or outcome of interest for case-control or cohort studies, respectively.

\section{Results}

\section{Study Selection}

A diagram illustrating the flow of citations through the SR process is provided in Figure 1. A total of 4,845 citations were identified in the full search. Seventy-eight publications reporting insulin adherence measures in adults (aged $\geq 18$ years) with T1DM or T2DM were included in the final dataset. 
Quality Measure

Outcome of

Interest

Alc

Blood pressure

Percentage of members aged 18 to 75 years with diabetes (types 1 and 2) whose most recent blood pressure reading is $<140 / 90 \mathrm{~mm} \mathrm{Hg}$ during the measurement year

centage

ment year

Percentage of members aged 18 to 75 years with diabetes (types 1 and 2) who had Alc control (<8.0\%)

Percentage of patients aged 18 to 75 years with diabetes (types 1 and 2) who received an Alc test during the measurement year

Percentage of patients aged 18 to 75 years with diabetes who had Alc $>9.0 \%$ during the measurement year

Percentage of patients who were dispensed medication for

ACE inhibitor or ARB or DRI renin-angiotensin antagonist

Percentage of members aged 18 to 75 years with diabetes (types 1 and 2) who received an LDL cholesterol test during the measurement year

LDL

Percentage of patients aged 18 to 75 years with diabetes whose LDL cholesterol was adequately controlled

$(<100 \mathrm{mg} / \mathrm{dL})$ during the measurement period

Percentage of patients aged 18 to 75 years with diabetes who had a foot exam during the measurement period

Foot exam

Percentage of patients aged 18 to 75 years with diabetes who had a retinal or dilated eye exam by an eye care professional during the measurement period or a negative retinal exam (no evidence of retinopathy) in

Eye exam the 12 months prior to the measurement period

Coronary artery disease

Percentage of patients aged $\geq 18$ years with a diagnosis of coronary artery disease seen within a 12-month period who also have diabetes or a current or prior $\mathrm{LVEF}<40 \%$ who were prescribed ACE inhibitor or ARB therapy

Foot and

ankle care

Percentage

logical examination of their lower extremities during 1 or more office visits within 12 months

Percentage of patients aged $\geq 18$ years with a diagnosis of diabetes mellitus who were evaluated for proper footwear and sizing during 1 or more office visits within 12 months

Short-term complications admission rate

Admissions for a principal diagnosis of diabetes with short-term complications (ketoacidosis, hyperosmolarity, or coma) per 100,000 population aged $\geq 18$ years. Excludes obstetric admissions and transfers from other institutions

Percentage of patients aged $\geq 18$ years with a diagnosis of diabetic retinopathy who had a dilated macular or fundus exam performed with documented communication to the physician who manages the ongoing

Diabetic retinopathy

care of the patient

within 12 months

Percentage of patients aged $\geq 18$ years with a diagnosis of diabetic retinopathy who had a dilated macular or fundus exam performed that included documentation of the level of severity of retinopathy and the presence or absence of macular edema during 1 or more office visits within 12 months

Percentage of patients aged 18 to 75 years with diabetes who had a nephropathy screening test or evidence

Nephropathy

of nephropathy during the measurement period

Percentage of adult diabetes patients who have optimally managed modifiable risk factors (Alc, blood pressure, statin use, tobacco nonuse and daily aspirin or antiplatelet use for patients with diagnosis of ischemic vascular disease) with the intent of preventing or reducing future complications associated with poorly

Optimal diabetes care managed diabetes. Patients aged 18-75 years with a diagnosis of diabetes who meet all the numerator target of this composite measure: Alc $<8.0$, LDL $<100$, blood pressure $<140 / 90$, tobacco nonuser and for patients with diagnosis of ischemic vascular disease daily aspirin use unless contraindicated

Taking diabetes medication as directed Percentage of patients $\geq 18$ years who met the PDC threshold of $80 \%$ during the measurement year. A performance rate is calculated separately for the following medication categories: RAS antagonists, diabetes medications, statins
Quality Programs

Using the Measure

- Meaningful Use

- HEDIS

- Medicaid Adult Core Set

- MA Star Rating

- HEDIS

- Meaningful Use

- MSSP

- PQRS

- MA Star Rating

- HEDIS

- MA Star Rating

- Medicaid Adult Core Set

- MA Star Rating

- MA Star Rating

- HEDIS

- Meaningful Use

- PQRS

- HEDIS

- Meaningful Use

- MSSP

- PQRS

- MA Star Rating

- HEDIS

- Meaningful Use

- PQRS

- MSSP

- PQRS

- PQRS

- PQRS

- Medicaid Adult Core Set

- Meaningful Use

- PQRS

- Meaningful Use

- PQRS

- MA Star Rating

- HEDIS

- Meaningful Use

- PQRS

- PQRS

\section{- MA Star Rating}

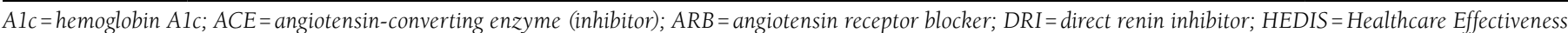

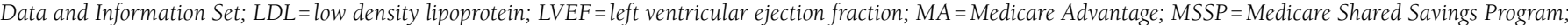
$N Q F=$ National Quality Forum; PDC= proportion of days covered; PQRS = Physician Quality Reporting System; RAS =renin-angiotensin system. 


\section{TABLE 2 Eligibility Criteria for the Systematic Review}

\begin{tabular}{|c|c|c|}
\hline Criteria & Include & Exclude \\
\hline Population & $\begin{array}{l}\text { Adults (aged } \geq 18 \text { years) with type } 1 \text { or type } 2 \\
\text { diabetes as defined in study }\end{array}$ & $\begin{array}{l}\text { - Pediatric populations } \\
\text { - Studies reporting only results for mixed populations (i.e., part of the } \\
\text { population not meeting the inclusion criteria) }\end{array}$ \\
\hline Intervention \& comparators & • Insulin & - Studies reporting on adherence measures of mixed treatments \\
\hline Outcomes & - Methods to measure adherence to insulin & $\begin{array}{l}\text { - Studies reporting only adherence outcomes/rates without reporting meth- } \\
\text { ods of how these were measured }\end{array}$ \\
\hline Study design & $\begin{array}{l}\text { - Observational studies } \\
\text { - Database claims analyses } \\
\text { - Modeling studies }\end{array}$ & $\begin{array}{l}\text { - Randomized controlled trials } \\
\text { - Reviews } \\
\text { - Letters, editorials, news } \\
\text { - Case studies on a single case }\end{array}$ \\
\hline
\end{tabular}

Most studies used retrospective claims cohorts, were conducted in the United States (61 studies), and were industry sponsored. The majority (58 studies) included patients with T2DM, 2 included T1DM patients, 10 included both, and the remaining did not report diabetes type. The mean population age ranged between 37.4 and 74.6 years. Most studies investigated any insulin treatment, with insulin type not specified, and the time period of most analyses was 1 year. The overall quality of the cohort studies was generally high, with many achieving 7 stars when using the NOS.

\section{Adherence Measures Commonly Reported}

Table 3 lists the adherence measures most commonly reported, their definitions, and areas of divergence between studies. The main areas of divergence were the denominator used when calculating the medication possession ratio (MPR), the definition of the refill gap while measuring persistence, and the additional assumptions used when calculating the PDC (e.g., imputation of missing days supply). Although not generally considered a direct measure of adherence, daily average consumption (DACON) was reported in 12 studies alongside the methods described above, and usually only for those patients established as adherent. All identified methods to measure adherence were indirect, with no studies identified that measured adherence directly through observation of medication taking, return of device used to inject the medication, or biological fluid samples.

Medication Possession Ratio. Twenty-two studies measured adherence using MPR. ${ }^{16-37}$ The numerator used to calculate MPR was consistent in 21 studies, ${ }^{16-19,21-37}$ whereas the denominator varied. Denominators included number of days between first fill and last fill in 2 studies $^{17,32}$; between first and last fill plus the days supply of the last fill in 3 studies $^{19,27,29}$; from first fill date to either the end of the last day of supplied medication during the study period or the end of the study period (whichever came first) in 1 study $^{33}$; and the analysis period in 15 of the studies. ${ }^{16,18,21-26,28,30,31,34-37}$ Table 3 shows a summary of the denominators used. In 1 study, the method used to calculate the MPR was not reported. ${ }^{20}$
Adjusted Medication Possession Ratio. An adjusted MPR was used in 11 studies to account for potential difference in pack sizes across pens and vials. ${ }^{30,31,35-43}$ Adjusted MPRs were calculated by analyzing the distribution of data by product and method of administration. The observed MPR was multiplied by the ratio of either the mean ( $\mathrm{N}=10$ studies) or median $(\mathrm{N}=1$ study) time between claims divided by the mean or median pharmacy reported days supply. Five of the studies reported adherence rates using both the traditional and adjusted MPR method. ${ }^{35-38,42}$ Comparison of both methods showed that the adherence increased when measured using the adjusted MPR. ${ }^{35-38,42}$ In Grabner et al. (2013), adherence was similar between pen and vial cohorts when measured using the traditional MPR method; however, when measured according to adjusted MPR, adherence was statistically significantly different between groups $(P<0.001){ }^{42}$

Proportion of Days Covered. Ten studies measured adherence using the PDC.44-53 PDC was measured using the traditional method in 8 studies, ${ }^{44,46-49,51-53}$ and in 1 study PDC methodology was not reported. ${ }^{50}$ In Donnelly et al. (2007), the authors used a method resembling PDC, although it was not specifically termed PDC. ${ }^{45}$

Assumptions were reported in several PDC studies. Consistent with the PDC approach, which prohibits the possibility of having a PDC $>1,4$ studies reported appending days of overlap to the previous prescription's end, where overlaps existed. ${ }^{49,51,53,54}$ In Lee et al. (2011), data on the days supply were missing and therefore, the average days supply was imputed. ${ }^{49}$ In Gibson et al. (2010), if a patient switched medication within a therapeutic class, it was assumed the remainder of the previous prescription was discarded and coverage commenced with the supply of the new medication. It was also assumed that days in hospital were considered adherent days. To account for the potential that the days supply of insulin might not indicate the full extent of coverage, a multiplier to reflect the average time between insulin prescriptions was applied. ${ }^{48}$ In both Eby et al. (2013) and Eby et al. (2014), 2 variations from the traditional PDC method were applied. The first calculated PDC based on the proportion of days when 


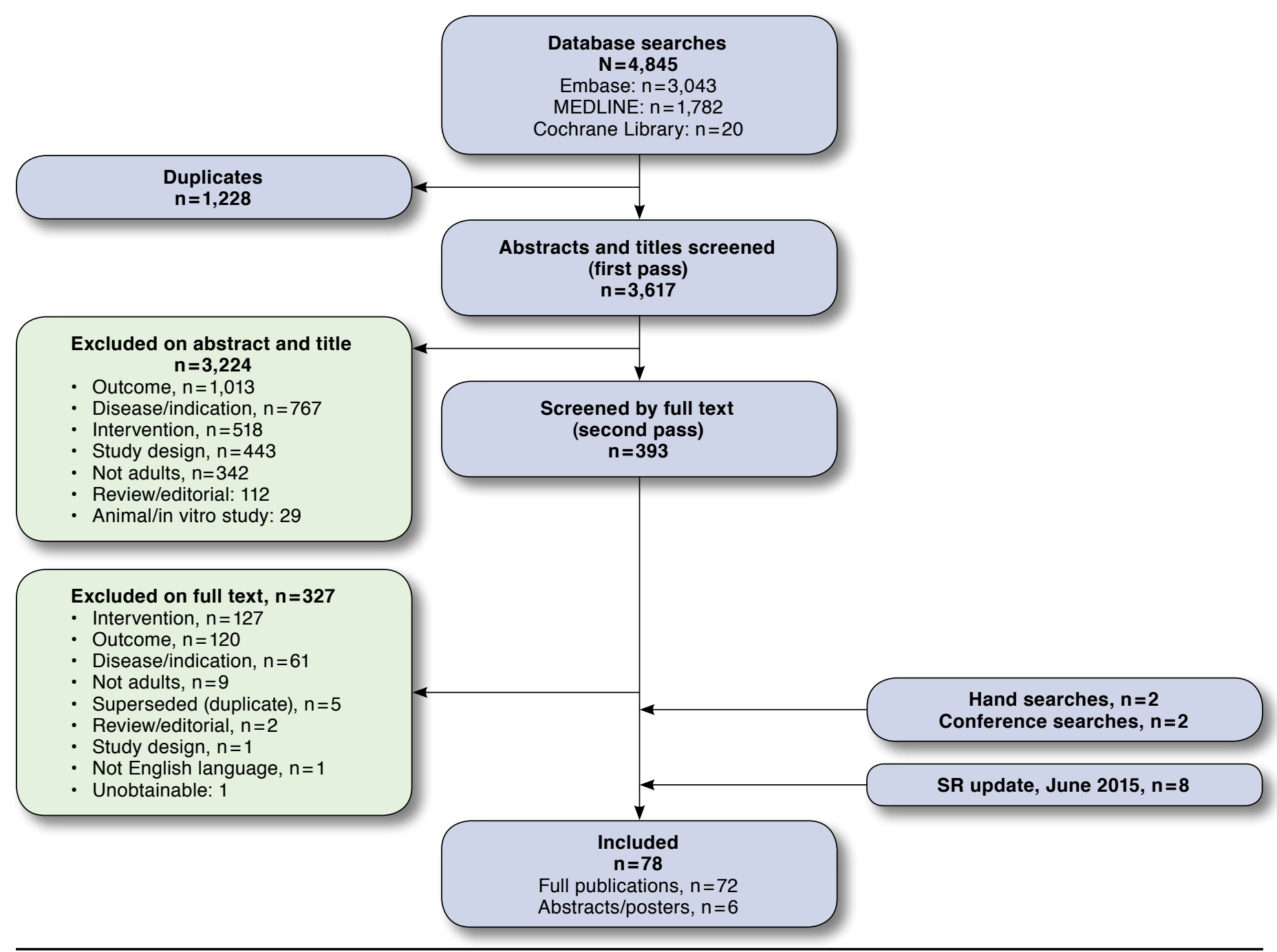

SR = systematic review

a minimum of each patient's index daily dose was available (PDCindex). ${ }^{46,47}$ The second analysis, which aimed to describe the level of adherence to high-dose regimens, calculated PDC based on the proportion of days for which $>200$ units/day of insulin were available (PDC200) in Eby et al. (2013) ${ }^{46}$ and the proportion of days for which $\geq 150$ units/day of insulin were available (PDC150) in Eby et al. (2014). ${ }^{47}$

Persistence. A total of 23 studies (24 publications) reported on methods to measure persistence with treatment. ${ }^{11,17,24,30,31,35-37,39-43,54-64}$ Fifteen studies (65\%) used the same method to measure treatment persistence $e^{30,31,35-37,39,41-43,56,58-61,64 \text { : }}$ the percentage of patients who did not discontinue their treatment, with medication considered discontinued if the prescription was not filled within an expected time of medication coverage. Whereas there was a consistent definition to the expected time of medication coverage (a percentile of the time, stratified by the metric quantity supplied, between the first and second fills among patients with at least 1 refill), the percentile of time varied across studies. Eleven studies used the 90th percentile of time (sensitivity analysis: 75 th and 95th percentile of time). ${ }^{30,31,35-37,39,42,43,60,61,64}$ Three studies used the 75 th percentile of time (sensitivity analyses: 50th and 90th percentile of time), ${ }^{56,58,59}$ and 1 study used the 75 th percentile of time (sensitivity analysis: 90th and 95th percentile of time). ${ }^{41}$ When measuring the percentage of patients discontinuing treatment, the number of persistent days (number of days between the index date and the discontinuation/switch date) was also calculated. 


\section{TABLE 3 Most Commonly Reported Adherence Measures}

\begin{tabular}{|c|c|c|c|c|}
\hline $\begin{array}{l}\text { Adherence } \\
\text { Measures }\end{array}$ & Calculation Method & $\begin{array}{c}\text { Number of } \\
\text { References } \\
\text { Using This } \\
\text { Measure }\end{array}$ & Areas of Divergence & $\begin{array}{c}\text { Adherence Measure Advantages and } \\
\text { Disadvantages }\end{array}$ \\
\hline $\begin{array}{l}\text { Medication } \\
\text { possession } \\
\text { ratio }\end{array}$ & $\begin{array}{l}\text { Using prescription data from pharmacy claims } \\
\text { MPR }=\frac{\text { Total days supply of all prescriptions in defined period }}{\text { Number of days in the defined period }} \\
\text { Value between } 0 \text { and } 1,1 \text { being } 100 \% \text { adherent } \\
\text { Patients are usually considered adherent at an } \\
\text { MPR } \geq 0.8(80 \%) .18\end{array}$ & $\mathrm{n}=22^{16-37}$ & $\begin{array}{l}\text { Denominator as number } \\
\text { of days from first fill } \\
\text { until last fill or } 1 \text { year } \\
\text { or otherwise modified } \\
\text { (e.g., excluding days } \\
\text { hospitalized or overlap } \\
\text { in fills) }\end{array}$ & $\begin{array}{l}\text { Advantages: } \\
\text { - Uses pharmacy claims data } \\
\text { - Relatively easy to calculate } \\
\text { Disadvantages: } \\
\text { - Presence of pharmacy claim does not indi- } \\
\text { cate medication taken } \\
\text { - Can overestimate adherence if patients } \\
\text { refill prescriptions early } \\
\text { - Pharmacy claims data affected by wastage } \\
\text { and stockpiling } \\
\text { - Relies on days supply in calculation }\end{array}$ \\
\hline $\begin{array}{l}\text { Adjusted } \\
\text { medication } \\
\text { possession } \\
\text { ratio } \\
\text { method }\end{array}$ & $\begin{array}{l}\text { Using prescription data from pharmacy claims } \\
\text { Adjusted MPR }=\text { MPR } \times \frac{\text { Average days between prescription refills }}{\text { Average days supply }} \\
\text { Used to account for the differences in pack sizes } \\
\text { between insulin devices }\end{array}$ & $\begin{array}{l}\mathrm{n}=11^{30,31} \\
35-43\end{array}$ & $\begin{array}{l}\text { Correct the issue that } \\
\text { almost all prescriptions } \\
\text { are dispensed with a } \\
\text { 30-day supply period } \\
\text { even though patients } \\
\text { may have more insulin } \\
\text { than ordered due to } \\
\text { variations in their daily } \\
\text { dosing (dependent on } \\
\text { body weight and glyce- } \\
\text { mic control).35 }\end{array}$ & $\begin{array}{l}\text { Advantages: } \\
\text { - Uses pharmacy claims data } \\
\text { - Ability to adjust for differences in insulin } \\
\text { pack sizes and correct for prescriptions } \\
\text { dispensed with } 30 \text {-day supply period } \\
\text { Disadvantages: } \\
\text { - Pharmacy claims data affected by wastage } \\
\text { and stockpiling } \\
\text { - Adjustment factor not standardized } \\
\text { - Relies on days supply in calculation }\end{array}$ \\
\hline $\begin{array}{l}\text { Proportion } \\
\text { of days } \\
\text { covered }\end{array}$ & $\begin{array}{l}\text { Using prescription data from pharmacy claims } \\
\text { PDC }=\frac{\text { Days supplied between first and last prescription }}{\text { Days between first fill and end of the measurement period }} \\
\text { Patients are usually defined as adherent if they have a } \\
\text { PDC } \geq 80 \% .65 \\
\text { Endorsed by the PQA as the preferred method for } \\
\text { measuring medication adherence } 44\end{array}$ & $\mathrm{n}=10^{44-53}$ & $\begin{array}{l}\text { Can adjust for overlap- } \\
\text { ping prescriptions, } \\
\text { different types of } \\
\text { medication and adjust } \\
\text { for proportion of days } \\
\text { spent in hospital. } \\
\text { When calculating the } \\
\text { PDC for a single drug, } \\
\text { it can be considered the } \\
\text { same as the MPR mea- } \\
\text { sure that is calculated } \\
\text { using the full analysis } \\
\text { period as the denomi- } \\
\text { nator, if the MPR is } \\
\text { capped at } 1.49\end{array}$ & $\begin{array}{l}\text { Advantages: } \\
\text { - Uses pharmacy claims data } \\
\text { - Method endorsed by the PQA as preferred } \\
\text { method for measuring adherence } \\
\text { - Accounts for overlap in days supply } \\
\text { - More accurate when calculating adherence } \\
\text { to medication regimens } \\
\text { Disadvantages: } \\
\text { - Does not account for differences in insulin } \\
\text { pack size } \\
\text { - Pharmacy claims data affected by wastage } \\
\text { and stockpiling } \\
\text { - Relies on days supply in calculation }\end{array}$ \\
\hline Persistence & $\begin{array}{l}\text { Using prescription data from pharmacy claims: } \\
\text { Patient remaining on the study drug for the entire } \\
\text { follow-up period without discontinuation or switch- } \\
\text { ing after initiation of the index drug }\end{array}$ & $\begin{array}{l}\mathrm{n}=2411,17 \\
24,30,31,35-37 \\
39-43,54-64\end{array}$ & $\begin{array}{l}\text { Time between refills } \\
\text { (gaps) and proportion } \\
\text { of patients not refilling } \\
\text { in time }\end{array}$ & $\begin{array}{l}\text { Advantages: } \\
\text { - Uses pharmacy claims data } \\
\text { - Assesses treatment discontinuation } \\
\text { Disadvantages: } \\
\text { - Pharmacy claims data affected by wastage } \\
\text { and stockpiling } \\
\text { - Measure indicates patient is persistent but } \\
\text { does not measure compliance with physi- } \\
\text { cian's recommendations } \\
\text { - A predefined treatment gap is not suitable } \\
\text { for measuring persistence with injectables } \\
\text { due to variable-dose titration schedules } \\
\end{array}$ \\
\hline $\begin{array}{l}\text { Daily } \\
\text { average } \\
\text { consump- } \\
\text { tion }\end{array}$ & $\begin{array}{l}\text { Using prescription data from pharmacy claims } \\
\text { DACON }=\frac{\text { Total number of units dispensed }}{\text { Number of days between index date and date of last fill) }} \\
\text { where } \\
\text { Total units dispensed } \\
=\text { total milliliters dispensed for all prescriptions in } \\
\text { follow-up period } \times 100 \\
\text { No benchmark exists for DACON representing good } \\
\text { adherence. }\end{array}$ & $\begin{array}{l}\mathrm{n}=1230,31 \\
36-39,41-43 \\
56,60,64\end{array}$ & $\begin{array}{l}\text { Can adjust for units dis- } \\
\text { pensed and can account } \\
\text { for type of insulin } \\
\text { administered when } \\
\text { interpreting results }\end{array}$ & $\begin{array}{l}\text { Advantages: } \\
\text { - Uses pharmacy claims data } \\
\text { - Accounts for differences in insulin pack size } \\
\text { - Easily calculated } \\
\text { - Avoids use of days supply } \\
\text { Disadvantages: } \\
\text { - No validated threshold for good adherence } \\
\text { - Pharmacy claims data affected by wastage } \\
\text { and stockpiling } \\
\text { - Inter- and intrapersonal variability could } \\
\text { confound results in large datasets }\end{array}$ \\
\hline
\end{tabular}


TABLE 3 Most Commonly Reported Adherence Measures (continued)

\begin{tabular}{|c|c|c|c|c|}
\hline $\begin{array}{l}\text { Adherence } \\
\text { Measures }\end{array}$ & Calculation Method & $\begin{array}{c}\text { Number of } \\
\text { References } \\
\text { Using This } \\
\text { Measure }\end{array}$ & Areas of Divergence & $\begin{array}{c}\text { Adherence Measure Advantages and } \\
\text { Disadvantages }\end{array}$ \\
\hline $\begin{array}{l}\text { Morisky } \\
\text { Medication } \\
\text { Adherence } \\
\text { Scale }\end{array}$ & $\begin{array}{l}\text { Patient self-report measures with } 4 \text { or } 8 \text { items that } \\
\text { can be scored as either yes (0) or no ( } 1 \text { ) } \\
\text { MMAS- } 4 \text { scores: } 0=\text { high adherence; } 1-2=\text { medium } \\
\text { adherence; } 3-4=\text { low adherence } \\
\text { MMAS- } 8 \text { scores: } 0=\text { high adherence; } 1-2=\text { medium } \\
\text { adherence; } 3-8=\text { low adherence } 66\end{array}$ & $\begin{array}{l}\text { MMAS-4 } \\
n=667-72 \\
\text { and } \\
\text { MMAS-8 } \\
n=3^{73-75}\end{array}$ & Not applicable & $\begin{array}{l}\text { Advantages: } \\
\text { - Can be used to gather information on rea- } \\
\text { sons for nonadherence } \\
\text { - Self-reported surveys often increase com- } \\
\text { pliance, as the individuals know they are } \\
\text { being observed } \\
\text { Disadvantages: } \\
\text { - Self-reported measure where patients may } \\
\text { be dishonest } \\
\text { - Complexity and cost of data collection } \\
\text { when implementing as a quality measure }\end{array}$ \\
\hline
\end{tabular}

In Buysman et al. (2011), a similar method of using the expected time of medication coverage was used to measure persistence. However, in this study, an adjustment factor was used when measuring persistence to account for variations in insulin pack size and dosing schedules. ${ }^{40}$ An adjustment factor was calculated as the ratio of the 80th percentile of time between insulin claims divided by the 80th percentile of the pharmacy-reported days supply. The adjustment factor was then multiplied by the actual days supply reported on the pharmacy claim to calculate an adjusted days supply, and patients with a gap of 1 or more days in insulin therapy based on the adjusted days supply were defined as discontinuing therapy. ${ }^{40}$

In the remaining 7 studies, patients were considered nonpersistent with therapy if the time without treatment was of a predefined length. ${ }^{11,17,24,44,55,57,62}$ In Rashid et al. (2012), this measure was defined as the time to all-cause discontinuation, and a predefined gap of 90 days without any drug supply available was considered discontinuation. ${ }^{62}$ The following gaps were used in other included studies: 60 and 90 days, ${ }^{24}$ 60 days,$^{44}$ and 30 days. ${ }^{17,55}$ In Bonafede et al. (2011), persistence was calculated using 2 measures: if there was a 90-day gap in prescription fills, or if a specific number of refills did not occur within a prespecified time period..$^{57}$

Daily Average Consumption. A total of 12 studies measured DACON. ${ }^{30,31,36-39,41-43,56,60,64}$ All 12 studies used the traditional DACON method, with no studies applying additional assumptions. An expected level/benchmark of DACON or a threshold at which patients would be considered adherent was not reported. No studies reported a comparison of DACON among the adherent compared with the nonadherent.

Morisky Medication Adherence Scale. The Morisky Medication Adherence Scale (MMAS)-4 questionnaire was used to assess adherence in 6 of the included studies. ${ }^{67-72}$ The
MMAS-8 questionnaire was used to assess adherence in 3 of the included studies. ${ }^{73-75}$

\section{Other Adherence Measures}

In 20 studies, methods other than those described in Table 3 were used to measure adherence (data not shown). ${ }^{7,76-94}$

\section{Discussion}

This SR was designed to identify studies reporting methods to measure adherence to insulin treatment in patients with diabetes. Previous SRs have studied adherence to diabetes medication, but to our knowledge this is the first to focus specifically on methods to measure adherence to insulin in adults with diabetes for the purpose of consideration for a quality performance measure. Cramer et al. (2004) conducted an SR to determine the extent to which patients omit doses of medications prescribed for diabetes. ${ }^{95}$ However, as commented by Wens et al. (2004), an important database, Embase, was not searched in that SR, and therefore important studies may have been omitted. ${ }^{96}$ Other previous SRs focused on adherence rates, ${ }^{97}$ factors affecting adherence, ${ }^{98,99}$ improving adherence, ${ }^{100-103}$ or assessed adherence with oral medications only. ${ }^{104,105}$ One SR published in 2014 reviewed methods to measure medication adherence in patients with diabetes on oral hypoglycemic agents and/ or insulin in original research published between 2007 and $2013 .{ }^{106}$ The scope of our SR differed by excluding pediatric populations, oral medication, or RCTs as study design and includes publications since the year 2000. To our knowledge, none of the SRs aforementioned had the same objective.

\section{Limitations}

The SR was conducted using predefined eligibility criteria and conformed to Preferred Reporting Items for Systematic Reviews and Meta-Analyses (PRISMA) guidelines, ${ }^{107}$ which contributes 
to the robustness of the conclusions. There were some limitations in the SR methodology. The searches were restricted to identify only those studies published after the year 2000 . Searches were limited to 2000 onward, as outcomes research and quality measures for adherence would not have been studied in great depth or available to patients before this date. ${ }^{108}$

A factor influencing the generalizability of the data is the inclusion of studies that used databases, such as the PharMetrics database, the Thomson Reuters MarketScan database, and the Innovus IMPACT national managed care database. These studies used specific patient populations, and the data from these studies may not be generalizable to other populations.

\section{Challenges with Measuring Insulin Adherence}

There are advantages and disadvantages associated with the different methods to measure insulin adherence, which should be considered when assessing their applicability as a quality measure.

The MPR and PDC methods allow different ways to calculate the supply and possession of medication based on pharmacy claims data. The key strength of the adjusted MPR and adjusted PDC over the traditional MPR and PDC is the ability to adjust for differences in insulin pack sizes, and to correct for the fact that almost all insulin prescriptions are dispensed with a 30-day supply period even though patients may have more insulin than ordered due to variations in their daily dosing. This adjustment allows for a more accurate representation of how a patient adhered to the prescription as written by the prescriber. However, insulin adherence calculations from prescription claims data are particularly challenging, as such calculations are performed based on the days supply entered by the pharmacist during claim submission and adjudication. The days supply used for billing often does not match the clinically appropriate days supply because of issues such as irregular insulin dosing, sliding scale usage, and unit-based dispensing. While the reliability of the days supply primarily persists with pens, assuming a 28-day supply for vials because they should not be used beyond that due to shelf life limitations, is equally problematic from a quality measure perspective, as it is an additional assumption that would need to be made in any analysis.

Persistence can also be measured with pharmacy claims data. As described in the results, similar adjustment factors have been applied to persistence and adherence. The challenge with the use of any adjustment factor, whether associated with MPR, PDC, or persistence, is that the method is not entirely standardized because the adjustment factor is contingent on the distribution of each product and formulation within the population of interest. While this is feasible from the research perspective, it may be problematic when financial incentives or penalties are applied if a given insurance plan does or does not meet the metric.
We suggest that an adjusted MPR, PDC, or persistence analysis would need to be validated before considering use as a performance measure. Additionally, a cross-validation technique would need to be developed that could be applied randomly when used as part of performance measurement to minimize potential for human error due to the nonstandardized approach. In the interim, researchers should perform and report sensitivity analyses based on the distribution of data that informs any adjustments. In the case of PDC or MPR, analyses that adjust for both mean and median days supply and/or analyses that consider the lower and upper bounds of the $95 \%$ confidence interval when the mean is applied may be appropriate. For persistence, sensitivity analyses that consider a minimum $10 \%$ variation in the percentile of time period analyzed may be appropriate.

The insulin consumption as measured with DACON accounts for dose consumed; however, a limitation specifically with DACON is the lack of a validated threshold for good adherence. A large population with inter- and intrapersonal variability in insulin types and dose requirements complicates generalization of consumption requirements. Whereas DACON is traditionally measured over a persistent time period, it may be worth investigating whether a redefinition of the time period of interest is warranted in this context. For example, if DACON were calculated over a calendar year of interest rather than a persistent period of interest, it may be possible to identify a minimum threshold that correlates with both persistency and diabetes control (measured by hemoglobin Alc). While this hypothesis would need to be tested before further consideration of a revised DACON as a means to approximate adherence for performance measurement purposes, the objectivity of the DACON value is reassuring.

The measures using pharmacy claims data may be more reliable than those recorded from self-report questionnaires (such as MMAS), as the latter may be subject to reporting bias, and those patients reporting their medication consumption tend to overreport their adherence for various reasons. ${ }^{109-111}$ There is an added complexity associated with the implementation of selfreport questionnaires for quality measurement, as they require the need to survey either an entire population, which is likely not feasible, or they require appropriate adjustment to ensure plan representativeness if a random subsample is selected. At a plan level, this would require additional resources that may limit the uptake of the measure and will not provide patient adherence outliers for quality improvement interventions.

Claims data provide a practical approach to adherence calculation for quality reporting and are the current basis for the PQA diabetes metric used in the Medicare Star Ratings adherence calculation. The majority of included studies used a 1-year post-index period as follow-up time, and an adherence quality measure could use a calendar year as measuring period. However, using any of the calculation methods identified in 
this SR, pharmacy claims data may not accurately represent the medication supply and currently cannot reflect the appropriate timing and dosing of insulin administration. For this reason, we suggest that, in the long term, consideration is taken to modify database systems used to adjudicate reimbursement. While it is well understood these systems were borne out of a need to track and reimburse insurance claims, they have evolved to serve as research tools and analytical platforms for quality measurement. Allowing pharmacists to enter accurate clinical days supply for products, like insulin, in which there is variation between the reimbursed supply and actual supply available to a patient would enable tracking and reporting of insulin adherence. This tracking and reporting would therefore align the evolution of systems with that of health care, which can only serve to achieve the goal of managing costs while maintaining superior quality of care for the U.S. population.

\section{Role of Quality Measures in U.S. Government Health Care Reform}

Currently, the push for improving quality in health care is accelerating in the United States, and this has numerous implications for measuring adherence in diabetes. Plans from the Department of HHS include quality measure initiatives with a focus on improved outcome measures, patient experience measures, and other metrics such as care coordination, access, and delivery. These plans will consider gaps in quality measurement and applicability of measures across health care settings. Currently, CMS considers measures of adherence intermediate outcome metrics-surrogate measures for disease outcomes metrics. ${ }^{112}$

\section{Call for an Insulin Quality Measure}

Diabetes is one of the diseases targeted as priority by the National Quality Strategy and as such should continue to be a focus of quality measure development. ${ }^{113}$ Currently, several quality measures endorsed by NQF for diabetes include adherence measures, but not insulin adherence (Table 1). This gap is important, as a considerable proportion of patients with diabetes, particularly those with advanced disease, use insulin. A quality measure for appropriate use of insulin should therefore be considered.

Because improved disease outcomes (i.e., glycemic control, Alc levels) are considered of highest priority, and patients are the center of care delivery for insulin treatment, a link between outcome and insulin usage would be a relevant target for a quality measure, as it could serve as a gauge to understand the degree to which the health care team is able to partner with patients in improving their health-related engagement and activation. By addressing patient-centric barriers with adherence, specifically with insulin, costs due to microvascular complications may be reduced in the long term. Therefore, patient engagement and education will be essential to help develop and implement an insulin adherence quality measure. As part of the development process, additional studies confirming the validity of the new measure should be conducted in order to reach consensus.

\section{Conclusions}

This SR identifies a range of possible methods to measure adherence to insulin using pharmacy claims or patientreported questionnaires. We conclude that, while there is some potential based on what has previously been developed, without additional research or modification of current databases used to track claims and measure performance, none of these are currently appropriate for use as a quality measure for insulin adherence. The relevance of insulin adherence as an intermediate outcome for diabetes management is of high priority in the context of health care reform plans with measurable goals. Studies confirming the soundness of new measurement methodology should be conducted.

\section{Authors}

SAMUEL STOLPE, PharmD, Pharmacy Quality Alliance, Springfield, Virginia; MICHEL A. KROES, MSc, and NEIL WEBB, BSc Hons, DRG Abacus, Bicester, Oxfordshire, United Kingdom; and TAMI WISNIEWSKI, MPH, Novo Nordisk, Plainsboro, New Jersey.

AUTHOR CORRESPONDENCE: Neil Webb, BSc, DRG Abacus, 6 Talisman Rd., Bicester, Oxfordshire, OX26 6HR, UK. Tel.: 01869 355650; E-mail: nwebb@teamdrg.com

\section{DISCLOSURES}

Novo Nordisk paid DRG Abacus to complete the systematic review and manuscript and was involved in the study design, interpretation of data, and decision to publish the findings of the systematic review. Kroes and Webb report personal fees from Novo Nordisk during the conduct of the study and personal fees from DRG Abacus, outside of the submitted work. Webb is employed by DRG Abacus, and Kroes was employed by DRG Abacus at the time of this study. Wisniewski is an employee of Novo Nordisk, which funded the systematic review reported in this article, and also owns stocks in Novo Nordisk. Stolpe has nothing to disclose.

Study concept and design were contributed by Kroes, Webb, and Wisniewski, with assistance from Stolpe. Webb took the lead in data collection, along with Kroes, and data interpretation was performed by all the authors. The manuscript was written by Kroes, Webb, and Wisniewski, with assistance from Stolpe, and revised by Kroes, Stolpe, Wisniewski, and Webb.

\section{REFERENCES}

1. American Diabetes Association. 7. Approaches to glycemic treatment Diabetes Care. 2016;39(Suppl 1):S52-59.

2. Standards of medical care in diabetes-2015. Diabetes Care. 2015;38 (Suppl 1):S1-93.

3. Doggrell SA, Warot S. The association between the measurement of adherence to anti-diabetes medicine and the HbAlc. Int J Clin Pharm. 2014;36(3):488-97. 
4. Stratton IM, Adler AI, Neil HA, et al. Association of glycaemia with macrovascular and microvascular complications of type 2 diabetes (UKPDS 35): prospective observational study. BMJ. 2000;321(7258):405-12.

5. Currie CJ, Peyrot M, Morgan CL, et al. The impact of treatment noncompliance on mortality in people with type 2 diabetes. Diabetes Care. 2012;35(6):1279-84.

6. Peyrot M, Rubin RR, Kruger DF, Travis LB. Correlates of insulin injection omission. Diabetes Care. 2010;33(2):240-45.

7. Peyrot M, Barnett AH, Meneghini LF, Schumm-Draeger PM. Insulin adherence behaviours and barriers in the multinational Global Attitudes of Patients and Physicians in Insulin Therapy study. Diabet Med. 2012;29(5):682-89.

8. Polonsky WH, Fisher L, Guzman S, Villa-Caballero L, Edelman SV. Psychological insulin resistance in patients with type 2 diabetes: the scope of the problem. Diabetes Care. 2005;28(10):2543-45.

9. Ross SA, Tildesley HD, Ashkenas J. Barriers to effective insulin treatment: the persistence of poor glycemic control in type 2 diabetes. Curr Med Res Opin. 2011;27(Suppl 3):13-20.

10. Peyrot M, Skovlund SE, Landgraf R. Epidemiology and correlates of weight worry in the multinational Diabetes Attitudes, Wishes and Needs study. Curr Med Res Opin. 2009;25(8):1985-93.

11. Cooke CE, Lee HY, Tong YP, Haines ST. Persistence with injectable antidiabetic agents in members with type 2 diabetes in a commercial managed care organization. Curr Med Res Opin. 2010;26(1):231-38.

12. Centers for Disease Control and Prevention. National Diabetes Statistics Report, 2014. Available at: http://www.cdc.gov/diabetes/pubs/statsreport14/ national-diabetes-report-web.pdf. Accessed September 17, 2016.

13. Nau DP. Proportion of days covered (PDC) as a preferred method of measuring medication adherence. PQA Resources. Available at: http://www. pqaalliance.org/images/uploads/files/PQA\%20PDC\%20vs\%20\%20MPR.pdf. Accessed September 17, 2016.

14. Centers for Disease Control and Prevention. Age-Adjusted Percentage of Adults with Diabetes Using Diabetes Medication, by Type of Medication, United States, 1997-2011. Available at: http://www.cdc.gov/diabetes/statistics/meduse/fig2.htm. Accessed September 17, 2011.

15. Wells GA, Shea B, O'Connell D, et al. The Newcastle-Ottawa Scale (NOS) for assessing the quality of nonrandomised studies in meta-analyses. Available at: http://www.ohri.ca/programs/clinical_epidemiology/oxford.asp. Accessed September 17, 2016.

16. Chandran A, Bonafede MK, Nigam S, Saltiel-Berzin R, Hirsch LJ, Lahue BJ. Adherence to insulin pen therapy is associated with reduction in healthcare costs among patients with type 2 diabetes mellitus. Am Health Drug Benefits. 2015;8(3):148-58.

17. Cheen HH, Lim SH, Huang MC, Bee YM, Wee HL. Adherence to premixed insulin in a prefilled pen compared with a vial/syringe in people with diabetes in Singapore. Clin Ther. 2014;36(7):1043-53.

18. Chernew ME, Shah MR, Wegh A, et al. Impact of decreasing copayments on medication adherence within a disease management environment. Health Aff (Millwood). 2008;27(1):103-12.

19. Cobden D, Lee WC, Balu S, Joshi AV, Pashos CL. Health outcomes and economic impact of therapy conversion to a biphasic insulin analog pen among privately insured patients with type 2 diabetes mellitus. Pharmacotherapy. 2007;27(7):948-62.

20. Eby E, Lage MJ, Mitchell B. Patient characteristics and outcomes among individuals with type 2 diabetes: a comparison based upon adherence. Presented at: ISPOR 17th Annual International Meeting; June 2-6, 2012; Washington, DC. Available at: http://www.ispor.org/research_pdfs/40/pdffiles/PDB107.pdf. Accessed September 21, 2016.

21. Egede LE, Gebregziabher M, Echols C, Lynch CP. Longitudinal effects of medication nonadherence on glycemic control. Ann Pharmacother. 2014:48(5):562-70.
22. Egede LE, Gebregziabher M, Hunt KJ, et al. Regional, geographic, and racial/ethnic variation in glycemic control in a national sample of veterans with diabetes. Diabetes Care. 2011;34(4):938-43.

23. Egede LE, Lynch CP, Gebregziabher M, et al. Differential impact of longitudinal medication non-adherence on mortality by race/ethnicity among veterans with diabetes. J Gen Intern Med. 2013;28(2):208-15.

24. Fabunmi R, Nielsen LL, Quimbo R, et al. Patient characteristics, drug adherence patterns, and hypoglycemia costs for patients with type 2 diabetes mellitus newly initiated on exenatide or insulin glargine. Curr Med Res Opin. 2009;25(3):777-86

25. Gibson TB, Mahoney J, Ranghell K, Cherney BJ, McElwee N. Valuebased insurance plus disease management increased medication use and produced savings. Health Aff (Millwood). 2011;30(1):100-08.

26. Kleinman NL, Schaneman JL, Lynch WD. The association of insulin medication possession ratio, use of insulin glargine, and health benefit costs in employees and spouses with type 2 diabetes. J Occup Environ Med. 2008;50(12):1386-93.

27. Lee WC, Balu S, Cobden D, Joshi AV, Pashos CL. Medication adherence and the associated health-economic impact among patients with type 2 diabetes mellitus converting to insulin pen therapy: an analysis of third-party managed care claims data. Clin Ther. 2006;28(10):1712-25.

28. Malmenäs M, Bouchard JR, Langer J. Retrospective real-world adherence in patients with type 2 diabetes initiating once-daily liraglutide $1.8 \mathrm{mg}$ or twice-daily exenatide $10 \mu \mathrm{g}$. Clin Ther. 2013;35(6):795-807.

29. McAdam-Marx C, Bellows BK, Wygant GD, et al. Associations between claims based adherence, weight loss and, glycemic control in patients with type 2 diabetes. Presented at: ISPOR 18th Annual International Meeting; May 18-22, 2013; New Orleans, LA. Available at: http://www.ispor.org/ research_pdfs/43/pdffiles/PDB67.pdf. Accessed September 21, 2016.

30. Miao R, Wei W, Baser O, Xie L. Real world outcomes of adding rapidacting insulin versus switching to analog premix insulin among U.S. patients with type 2 diabetes treated with insulin glargine. Patient Prefer Adherence. 2013;7:951-60.

31. Miao R, Wei W, Lin J, Xie L, Baser O. Does device make any difference? A real-world retrospective study of insulin treatment among elderly patients with type 2 diabetes. J Diabetes Sci Technol. 2014;8(1):150-58.

32. Pawaskar MD, Camacho FT, Anderson RT, Cobden D, Joshi AV, Balkrishnan R. Health care costs and medication adherence associated with initiation of insulin pen therapy in Medicaid-enrolled patients with type 2 diabetes: a retrospective database analysis. Clin Ther. 2007;29 Spec No:1294-305.

33. Sherman BW, Sekili A, Prakash ST, Rausch CA. Physician-specific variation in medication adherence among diabetes patients. Am J Manag Care. 2011;17(11):729-36.

34. Thiebaud P, Demand M, Wolf SA, Alipuria LL, Ye Q, Gutierrez PR. Impact of disease management on utilization and adherence with drugs and tests: the case of diabetes treatment in the Florida: a Healthy State (FAHS) program. Diabetes Care. 2008;31(9):1717-22.

35. Wang L, Wei W, Miao R, Xie L, Baser O. Real-world outcomes of U.S. employees with type 2 diabetes mellitus treated with insulin glargine or neutral protamine Hagedorn insulin: a comparative retrospective database study. BMJ Open. 2013;3(4).

36. Xie L, Wei W, Pan C, Du J, Baser O. A real-world study of patients with type 2 diabetes initiating basal insulins via disposable pens. Adv Ther 2011;28(11):1000-11.

37. Wei W, Zhou S, Miao R, et al. Much ado about nothing? A real-world study of patients with type 2 diabetes switching Basal insulin analogs. Adv Ther. 2014;31(5):539-60.

38. Baser O, Bouchard J, DeLuzio T, Henk H, Aagren M. Assessment of adherence and healthcare costs of insulin device (FlexPen) versus conventional vial/syringe. Adv Ther. 2010;27(2):94-104. 
39. Baser O, Tangirala K, Wei W, Xie L. Real-world outcomes of initiating insulin glargine-based treatment versus premixed analog insulins among U.S. patients with type 2 diabetes failing oral antidiabetic drugs. Clinicoecon Outcomes Res. 2013;5:497-505.

40. Buysman E, Conner C, Aagren M, Bouchard J, Liu F. Adherence and persistence to a regimen of basal insulin in a pre-filled pen compared to vial/syringe in insulin-naïve patients with type 2 diabetes. Curr Med Res Opin. 2011;27(9):1709-17.

41. Cao Z, Thomson E, Ling Z, Miao R, Wei W. Does device matter and at what cost? Real-world comparative study of insulin glargine treatment using disposable pen versus vial/syringe in Medicaid patients with type-2 diabetes mellitus. Value Health. 2013;16(3):A156.

42. Grabner M, Chu J, Raparla S, Quimbo R, Zhou S, Conoshenti J. Clinical and economic outcomes among patients with diabetes mellitus initiating insulin glargine pen versus vial. Postgrad Med. 2013;125(3):204-13.

43. Xie L, Zhou S, Wei W, Gill J, Pan C, Baser O. Does pen help? A realworld outcomes study of switching from vial to disposable pen among insulin glargine-treated patients with type 2 diabetes mellitus. Diabetes Technol Ther. 2013;15(3):230-36.

44. Curkendall SM, Thomas N, Bell KF, Juneau PL, Weiss AJ. Predictors of medication adherence in patients with type 2 diabetes mellitus. Curr Med Res Opin. 2013;29(10):1275-86.

45. Donnelly LA, Morris AD, Evans JM; DARTS/MEMO collaboration. Adherence to insulin and its association with glycaemic control in patients with type 2 diabetes. QJM. 2007;100(6):345-50.

46. Eby EL, Wang P, Curtis BH, et al. Cost, healthcare resource utilization, and adherence of individuals with diabetes using U-500 or U-100 insulin: a retrospective database analysis. J Med Econ. 2013;16(4):529-38.

47. Eby EL, Zagar AJ, Wang P, et al. Healthcare costs and adherence associated with human regular U-500 versus high-dose U-100 insulin in patients with diabetes. Endocr Pract. 2014;20(7):663-70.

48. Gibson TB, Song X, Alemayehu B, et al. Cost sharing, adherence, and health outcomes in patients with diabetes. Am J Manag Care. 2010;16(8):589-600.

49. Lee LJ, Li Q, Reynolds MW, Pawaskar MD, Corrigan SM. Comparison of utilization, cost, adherence, and hypoglycemia in patients with type 2 diabetes initiating rapid-acting insulin analog with prefilled pen versus vial/ syringe. J Med Econ. 2011;14(1):75-86

50. Nair KV, Miller K, Saseen J, Wolfe P, Allen RR, Park J. Prescription copay reduction program for diabetic employees: impact on medication compliance and healthcare costs and utilization. Am Health Drug Benefits. 2009;2(1):14-24.

51. Pelletier EM, Pawaskar M, Chapman R. Medication adherence and medical costs associated with exenatide bid versus liraglutide: a retrospective database analysis. Value Health. 2012;15(4):A179-80.

52. Ryan JG, Fedders M, Jennings T, Vittoria I, Yanes M. Clinical outcomes and incremental costs from a medication adherence pilot intervention targeting low-income patients with diabetes at risk of cost-related medication nonadherence. Clin Ther. 2014;36(12):1991-2002.

53. Zeng F, An JJ, Scully R, Barrington C, Patel BV, Nichol MB. The impact of value-based benefit design on adherence to diabetes medications: a propensity score-weighted difference in difference evaluation. Value Health. 2010;13(6):846-52

54. Curkendall S, Patel V, Gleeson M, Campbell RS, Zagari M, Dubois R. Compliance with biologic therapies for rheumatoid arthritis: do patient outof-pocket payments matter? Arthritis Rheum. 2008;59(10):1519-26.

55. Ascher-Svanum H, Lage MJ, Perez-Nieves M, et al. Early discontinuation and restart of insulin in the treatment of type 2 diabetes mellitus. Diabetes Ther. 2014;5(1):225-42

56. Baser O, Wei W, Baser E, Xie L. Clinical and economic outcomes in patients with type 2 diabetes initiating insulin glargine disposable pen versus exenatide BID. J Med Econ. 2011;14(6):673-80.

57. Bonafede MM, Kalsekar A, Pawaskar M, et al. Insulin use and persistence in patients with type 2 diabetes adding mealtime insulin to a basal regimen: a retrospective database analysis. BMC Endocr Disord. 2011;11:3.
58. Davis KL, Tangirala M, Meyers JL, Wei W. Real-world comparative outcomes of U.S. type 2 diabetes patients initiating analog basal insulin therapy. Curr Med Res Opin. 2013;29(9):1083-91.

59. Davis SN, Wei W, Garg S. Clinical impact of initiating insulin glargine therapy with disposable pen versus vial in patients with type 2 diabetes mellitus in a managed care setting. Endocr Pract. 2011;17(6):845-52.

60. Grabner M, Wei W, Raparla S, et al. Real-world comparative effectiveness analysis of patients initiating injectable treatments for type 2 diabetes mellitus (T2DM): pilot data from the initiator study. Value Health. 2012;15(7):A494

61. Levin P, Wei W, Miao R, et al. Therapeutically interchangeable? A study of real-world outcomes associated with switching basal insulin analogues among U.S. patients with type 2 diabetes mellitus using electronic medical records data. Diabetes Obes Metab. 2015;17(3):245-53.

62. Rashid N, McCombs JS, Schwartz E. Effect of exenatide, pen insulin, and vial insulin on patient outcomes: a retrospective database analysis of persistence and first-year costs in a commercially insured population. Clin Ther. 2012;34(5):1145-58.

63. Wei W, Pan C, Xie L, Baser O. Real-world insulin treatment persistence among patients with type 2 diabetes. Endocr Pract. 2014;20(1):52-61.

64. Xie L, Zhou S, Pinsky BW, Buysman EK, Baser O. Impact of initiating insulin glargine disposable pen versus vial/syringe on real-world glycemic outcomes and persistence among patients with type 2 diabetes mellitus in a large managed care plan: a claims database analysis. Diabetes Technol Ther. 2014;16(9):567-75.

65. Choudhry NK, Shrank WH, Levin RL, et al. Measuring concurrent adherence to multiple related medications. AmJ Manag Care. 2009;15(7):457-64.

66. Morisky DE, Ang A, Krousel-Wood M, Ward HJ. Predictive validity of a medication adherence measure in an outpatient setting. J Clins Hypertens (Greenwich). 2008;10(5):348-54.

67. Adisa R, Fakeye TO. Effect of number and type of antidiabetes medications on adherence and glycemia of ambulatory type 2 diabetes patients in southwestern Nigeria. Pharm Pract (Granada). 2013;11(3):156-65.

68. DiBonaventura MD, Wintfeld N, Goren A. The association between nonadherence and HbAlc among type 2 diabetes patients using basal insulin analogues. Value Health. 2012;15(4):A182.

69. Grandy S, Fox KM, Hardy E, SHIELD Study Group. Association of Weight Loss and Medication Adherence Among Adults With Type 2 Diabetes Mellitus: SHIELD (Study to Help Improve Early evaluation and management of risk factors Leading to Diabetes). Curr Ther Res Clin Exp. 2013;75:77-82.

70. Jarab AS, Almrayat R, Alqudah S, et al. Predictors of non-adherence to pharmacotherapy in patients with type 2 diabetes. IntJ Clin Pharm. 2014;36(4):725-33.

71. Mitchell BD, Vietri J, Zagar A, Curtis B, Reaney M. Hypoglycaemic events in patients with type 2 diabetes in the United Kingdom: associations with patient-reported outcomes and self-reported HbAlc. BMC Endocr Disord. 2013;13(59).

72. Reach G, Le Pautremat V, Gupta S. Determinants and consequences of insulin initiation for type 2 diabetes in France: analysis of the National Health and Wellness Survey. Patient Prefer Adherence. 2013;7:1007-23.

73. Adisa R, Fakeye TO, Fasanmade A. Medication adherence among ambulatory patients with type 2 diabetes in a tertiary healthcare setting in southwestern Nigeria. Pharm Pract (Granada). 2011;9(2):72-81.

74. DiBonaventura M, Wintfeld N, Huang J, Goren A. The association between nonadherence and glycated hemoglobin among type 2 diabetes patients using basal insulin analogs. Patient Prefer Adherence. 2014;8:873-82.

75. Farsaei S, Radfar M, Heydari Z, Abbasi F, Qorbani M. Insulin adherence in patients with diabetes: risk factors for injection omission. Prim Care Diabetes. 2014;8(4):338-45. 
76. Ampudia-Blasco FJ, Galán M, Brod M. A cross-sectional survey among patients and prescribers on insulin dosing irregularities and impact of mild (self-treated) hypoglycemia episodes in Spanish patients with type 2 diabetes as compared to other European patients. Endocrinol Nutr. 2014;61(8):426-33.

77. Ayyagari R, Wei W, Cheng D, Pan C, Signorovitch J, Wu EQ. Effect of adherence and insulin delivery system on clinical and economic outcomes among patients with type 2 diabetes initiating insulin treatment. Value Health. 2015;18(2):198-205.

78. Blaha MJ, Elasy TA. Adherence to insulin and the risk of glucose deterioration. Diabetes Care. 2006;29(8):1982-83.

79. Brod M, Rana A, Barnett AH. Adherence patterns in patients with type 2 diabetes on basal insulin analogues: missed, mistimed and reduced doses. Curr Med Res Opin. 2012;28(12):1933-46.

80. Cramer JA, Pugh MJ. The influence of insulin use on glycemic control How well do adults follow prescriptions for insulin? Diabetes Care. 2005; 28(1):78-83.

81. Elliott DJ, Robinson EJ, Anthony KB, Stillman PL. Patient-centered outcomes of a value-based insurance design program for patients with diabetes. Popul Health Manag. 2013;16(2):99-106.

82. Erickson TN, Devine EB, O'Young TS, Hanson LJ, French B, Brennan C. Effect of switching medically vulnerable patients with uncontrolled diabetes from isophane insulin human to insulin glargine. Am J Health Syst Pharm. 2006;63(19):1862-71.

83. Kindmalm L, Melander A, Nilsson JL. Refill adherence of antihyperglycaemic drugs related to glucose control (HbAlc) in patients with type 2 diabetes. Acta Diabetol. 2007;44(4):209-13.

84. Kitzler TM, Bachar M, Skrabal F, Kotanko P. Evaluation of treatment adherence in type 1 diabetes: a novel approach. Eur J Clin Invest. 2007; 37(3):207-13.

85. Lerman I, Diaz JP, Ibarguengoitia ME, et al. Nonadherence to insulin therapy in low-income, type 2 diabetic patients. Endocr Pract. 2009;15(1):41-46.

86. Levit S, Toledano Y, Wainstein J. Improved glycaemic control with reduced hypoglycaemic episodes and without weight gain using longterm modern premixed insulins in type 2 diabetes. Int $J$ Clin Pract. 2011;65(2):165-71

87. Lorenzi GM, LaRue SM, Collins SE. Effects of a patient education support program on pramlintide adherence. Clinical Diabetes. 2011;29(1):17-24.

88. McAdam-Marx C, Bellows BK, Unni S, et al. Determinants of glycaemic control in a practice setting: the role of weight loss and treatment adherence (The DELTA Study). Int J Clin Pract. 2014;68(11):1309-17.

89. Mashitani T, Hayashino Y, Okamura S, et al. Patient-reported adherence to insulin regimen is associated with glycemic control among Japanese patients with type 2 diabetes: Diabetes Distress and Care Registry at Tenri (DDCRT 3). Diabetes Res Clin Pract. 2013;100(2):189-94.

90. Ogbera AO, Kuku SF. Insulin use, prescription patterns, regimens and costs.-a narrative from a developing country. Diabetol Metab Syndr. 2012;4(1):50.

91. Peyrot M, Barnett AH, Meneghini LF, Schumm-Draeger PM. Factors associated with injection omission/non-adherence in the Global Attitudes of Patients and Physicians in Insulin Therapy study. Diabetes Obes Metab. 2012;14(12):1081-87.

92. Smith CB, Choudhary P, Pernet A, Hopkins D, Amiel SA. Hypoglycemia unawareness is associated with reduced adherence to therapeutic decisions in patients with type 1 diabetes: evidence from a clinical audit. Diabetes Care. 2009;32(7):1196-98

93. Turan B, Osar Z, Molzan Turan J, Damci T, Ilkova H. The role of coping with disease in adherence to treatment regimen and disease control in type 1 and insulin treated type 2 diabetes mellitus. Diabetes Metab. 2002;28(3):186-93.

94. Vijan S, Hayward RA, Ronis DL, Hofer TP. Brief report: the burden of diabetes therapy: implications for the design of effective patient-centered treatment regimens. J Gen Intern Med. 2005;20(5):479-82.
95. Cramer JA. A systematic review of adherence with medications for diabetes. Diabetes Care. 2004;27(5):1218-24.

96. Wens J, Vermeire E, Van Royen P, Hearnshaw H. A systematic review of adherence with medications for diabetes: response to Cramer. Diabetes Care. 2004;27(9):2284; author reply 2285.

97. Lee WC, Balu S, Cobden D, Joshi AV, Pashos CL. Prevalence and economic consequences of medication adherence in diabetes: a systematic literature review. Manag Care Interface. 2006;19(7):31-41.

98. Davies MJ, Gagliardino JJ, Gray LJ, Khunti K, Mohan V, Hughes R. Realworld factors affecting adherence to insulin therapy in patients with Type 1 or Type 2 diabetes mellitus: a systematic review. Diabet Med. 2013;30(5):512-24.

99. Krass I, Schieback P, Dhippayom T. Adherence to diabetes medication: a systematic review. Diabet Med. 2015;32(6):725-37.

100. Antoine SL, Pieper D, Mathes T, Eikermann M. Improving the adherence of type 2 diabetes mellitus patients with pharmacy care: a systematic review of randomized controlled trials. BMC Endocr Disord. 2014;14:53.

101. Williams JL, Walker RJ, Smalls BL, Campbell JA, Egede LE. Effective interventions to improve medication adherence in Type 2 diabetes: a systematic review. Diabetes Manag (Lond). 2014;4(1):29-48.

102. Sapkota S, Brien JA, Greenfield J, Aslani P. A systematic review of interventions addressing adherence to anti-diabetic medications in patients with type 2 diabetes-impact on adherence. PLoS One. 2015;10(2):e0118296.

103. Vignon Zomahoun HT, de Bruin M, Guillaumie L, et al. Effectiveness and content analysis of interventions to enhance oral antidiabetic drug adherence in adults with type 2 diabetes: systematic review and meta-analysis. Value Health. 2015;18(4):530-40.

104. Hutchins V, Zhang B, Fleurence RL, Krishnarajah G, Graham J. A systematic review of adherence, treatment satisfaction and costs, in fixed-dose combination regimens in type 2 diabetes. Curr Med Res Opin. 2011;27(6):1157-68.

105. Peeters B, Van Tongelen I, Boussery K, Mehuys E, Remon JP, Willems S. Factors associated with medication adherence to oral hypoglycaemic agents in different ethnic groups suffering from type 2 diabetes: a systematic literature review and suggestions for further research. Diabet Med. 2011;28(3):262-75.

106. Clifford S, Perez-Nieves M, Skalicky AM, Reaney M, Coyne KS. A systematic literature review of methodologies used to assess medication adherence in patients with diabetes. Curr Med Res Opin. 2014;30(6):1071-85.

107. Moher D, Liberati A, Tetzlaff J. Preferred reporting items for systematic reviews and meta-analyses: the PRISMA statement. PLoS Med. 2009;6(7):e1000097.

108. Fairman KA. Evaluating medication adherence: Which measure is right for your program? J Manag Care Pharm. 2000;6(6):499-506. Available at: http://www.jmcp.org/doi/abs/10.18553/jmcp.2000.6.6.499.

109. Garber MC, Nau DP, Erickson SR, Aikens JE, Lawrence JB. The concordance of self-report with other measures of medication adherence: a summary of the literature. Med Care. 2004:42(7):649-52.

110. Stirratt MJ, Dunbar-Jacob J, Crane HM, et al. Self-report measures of medication adherence behavior: recommendations on optimal use. Transl Behav Med. 2015;5(4):470-82.

111. Shi L, Liu J, Koleva Y, Fonseca V, Kalsekar A, Pawaskar M. Concordance of adherence measurement using self-reported adherence questionnaires and medication monitoring devices. Pharmacoeconomics. 2010;28(12):1097-107.

112. Centers for Medicare \& Medicaid Services. Medicare 2016 Part C \& D star rating technical notes: first plan preview: draft. Updated - 08/05/2015 Available at: https://www.cms.gov/Medicare/Prescription-Drug-Coverage/ PrescriptionDrugCovGenIn/Downloads/2016-Technical-Notes-Preview1-v2015_08_05.pdf. Accessed September 17, 2016.

113. U.S. Department of Health and Human Services. National quality strategy. Working for quality: achieving better health and health care for all Americans. September 2014. Available at: http://www.ahrq.gov/workingforquality/reports/ annual-reports/nqs2014annlrpt.pdf. Accessed September 17, 2016. 


\section{APPENDIX Systematic Review Search Strings}

\begin{tabular}{|c|c|c|}
\hline \multicolumn{3}{|c|}{ Search Strings Searched November 24, 2014} \\
\hline \multicolumn{2}{|c|}{ Embase, 1980 to present } & Results \\
\hline 1 & exp patient compliance/ & 103,209 \\
\hline 2 & exp medication compliance/ & 5,673 \\
\hline 3 & (complian* or adheren* or concordan* or persisten*).ti,ab. & 559,364 \\
\hline 4 & or/1-3 & 609,006 \\
\hline 5 & exp diabetes mellitus/ & 608,876 \\
\hline 6 & exp insulin dependent diabetes mellitus/ & 80,227 \\
\hline 7 & insulin dependent diabetes.ti,ab. & 22,076 \\
\hline 8 & TlDM.ti,ab. & 4,227 \\
\hline 9 & (diabetes mellitus and (type 1 or type $\mathrm{i}$ or type one)).ti,ab. & 19,690 \\
\hline 10 & (type 1 diabetes or type i diabetes).ti,ab. & 40,853 \\
\hline 11 & exp non insulin dependent diabetes mellitus/ & 148,504 \\
\hline 12 & insulin independent diabetes.ti,ab. & 133 \\
\hline 13 & T2DM.ti,ab. & 13,970 \\
\hline 14 & (diabetes mellitus and (type 2 or type ii or type two)).ti,ab. & 44,816 \\
\hline 15 & (type 2 diabetes or type ii diabetes).ti,ab. & 107,853 \\
\hline 16 & NIDDM.ti,ab. & 7,737 \\
\hline 17 & ((adult onset or adult-onset) and diabetes).mp. & 1,131 \\
\hline 18 & or/5-17 & 622,868 \\
\hline 19 & exp insulin/ & 242,264 \\
\hline 20 & insulin*.ti,ab. & 337,366 \\
\hline 21 & exp human insulin/ & 4,031 \\
\hline 22 & exp biphasic insulin/ & 568 \\
\hline 23 & exp bovine insulin/ & 702 \\
\hline 24 & human insulin.mp. & 10,147 \\
\hline 25 & biphasic insulin.mp. & 998 \\
\hline 26 & bovine insulin.mp. & 1,252 \\
\hline 27 & exp short acting insulin/ & 523 \\
\hline 28 & short acting insulin.mp. & 1,010 \\
\hline 29 & rapid acting insulin.mp. & 787 \\
\hline 30 & intermediate acting insulin.mp. & 291 \\
\hline 31 & long acting insulin.mp. or exp long acting insulin/ & 1,888 \\
\hline 32 & pre-mixed insulin.mp. & 54 \\
\hline 33 & humalog.mp. or exp insulin lispro/ & 4,115 \\
\hline 34 & exp insulin aspart/ & 3,480 \\
\hline 35 & (novolog or novorapid).mp. & 1,085 \\
\hline 36 & Apidra.mp. or exp insulin glulisine/ & 1,099 \\
\hline 37 & Regular humulin.mp. & 2 \\
\hline 38 & novolin.mp. & 536 \\
\hline 39 & Velosulin.mp. or exp neutral insulin/ & 3,123 \\
\hline 40 & NPH.mp. or exp isophane insulin/ & 7,917 \\
\hline 41 & Lantus.mp. or exp insulin glargine/ & 6,132 \\
\hline 42 & Levemir.mp. or exp insulin detemir/ & 2,414 \\
\hline 43 & Humulin.mp. & 1,606 \\
\hline 44 & exp insulin degludec/ or degludec.mp. & 456 \\
\hline 45 & tresiba.mp. & 25 \\
\hline 46 & ReliOn.mp. & 13 \\
\hline 47 & exp glucagon like peptide/ & 14,584 \\
\hline 48 & (glucagon like peptide or GLP).mp. & 17,530 \\
\hline 49 & exp exendin $4 /$ & 6,211 \\
\hline 50 & exenatide.mp. & 2,307 \\
\hline 51 & Byetta.mp. & 790 \\
\hline 52 & bydureon.mp. & 130 \\
\hline 53 & dulaglutide.mp. or exp dulaglutide/ & 136 \\
\hline 54 & trulicity.mp. & 2 \\
\hline
\end{tabular}




\section{APPENDIX Systematic Review Search Strings (continued)}

\begin{tabular}{|c|c|c|}
\hline \multicolumn{2}{|c|}{ Embase, 1980 to present } & \multirow{2}{*}{$\begin{array}{r}\text { Results } \\
3,328\end{array}$} \\
\hline 55 & liraglutide.mp. or exp liraglutide/ & \\
\hline 56 & (victoza or NN2211).mp. & 375 \\
\hline 57 & lixisenatide.mp. or exp lixisenatide/ & 357 \\
\hline 58 & lyxumia.mp. & 24 \\
\hline 59 & albiglutide.mp. or exp albiglutide/ & 307 \\
\hline 60 & (eperzan or tanzeum).mp. & 8 \\
\hline 61 & pramlintide.mp. or exp pramlintide/ & 1,145 \\
\hline 62 & symlin.mp. & 172 \\
\hline 63 & or/19-62 & 415,004 \\
\hline 64 & 4 and 18 and 63 & 8,022 \\
\hline 65 & exp rheumatoid arthritis/ & 146,130 \\
\hline 66 & (arthritis adj2 rheumat*).mp. & 163,187 \\
\hline 67 & (felty* adj2 syndrome).mp. & 927 \\
\hline 68 & (caplan* adj2 syndrome).mp. & 126 \\
\hline 69 & (sjogren* adj2 syndrome).mp. & 14,109 \\
\hline 70 & still* disease.mp. & 2,368 \\
\hline 71 & (spondylitis adj2 ankylosing).mp. & 20,873 \\
\hline 72 & or/65-71 & 189,589 \\
\hline 73 & exp disease modifying antirheumatic drug/ & 7,317 \\
\hline 74 & (disease modifying antirheumatic drug or DMARD*).mp. & 12,466 \\
\hline 75 & (biologic response modifiers or biologics).mp. & 9,297 \\
\hline 76 & exp recombinant interleukin 1 receptor blocking agent/ & 4,709 \\
\hline 77 & (anakinra or kineret).mp. & 2,522 \\
\hline 78 & exp golimumab/ & 2,396 \\
\hline 79 & (golimumab or cntol 48 or cnto 148 or simponi).mp. & 2,459 \\
\hline 80 & exp adalimumab/ & 16,255 \\
\hline 81 & (adalimumab or humira or trudexa).mp. & 16,523 \\
\hline 82 & exp abatacept/ & 4,511 \\
\hline 83 & (abatacept or ?rencia or CTLA4 or bms 188667 or bmsl88667).mp. & 7,035 \\
\hline 84 & exp etanercept/ & 19,709 \\
\hline 85 & (etanercept or enbrel or tnr00l or "tnr 001").mp. & 20,311 \\
\hline 86 & exp tocilizumab/ & 3,692 \\
\hline 87 & (atlizumab or tocilizumab or actemra or r 1569 or rl569).mp. & 4,337 \\
\hline 88 & exp certolizumab pegol/ & 2,978 \\
\hline 89 & ((certolizumab adj2 pegol) or cimzia or cdp870 cdp 870 or pha738144 or pha 738144).mp. & 3,021 \\
\hline 90 & or/73-89 & 50,821 \\
\hline 91 & 4 and 72 and 90 & 1,622 \\
\hline 92 & exp multiple sclerosis/ & 80,941 \\
\hline 93 & exp acute disseminated encephalomyelitis/ & 1,097 \\
\hline 94 & exp myelitis/ & 49,836 \\
\hline 95 & (multiple sclerosis or transverse myelitis or optic neuritis or devic or adem or neuromyelitis optica).mp. & 95,412 \\
\hline 96 & 'myelooptic neuropathy'mp. or exp myelooptic neuropathy/ & 4,095 \\
\hline 97 & exp demyelinating disease/ & 109,833 \\
\hline 98 & or/92-97 & 159,986 \\
\hline 99 & exp beta interferon/ & 17,543 \\
\hline 100 & (Interferon-beta or Interferon beta).mp. & 10,016 \\
\hline 101 & (betala interferon or betal interferon).mp. & 5,899 \\
\hline 102 & (avonex or rebif or betaferon or betaseron or extavia or plegridy).mp. & 3,596 \\
\hline 103 & glatiramer.mp. or exp glatiramer/ & 5,510 \\
\hline 104 & (cop-1 or cop 1 or copolymer 1 or copaxone).mp. & 1,777 \\
\hline 105 & or/99-104 & 26,734 \\
\hline 106 & 4 and 98 and 105 & 854 \\
\hline 107 & exp Human immunodeficiency virus infection/ & 303,243 \\
\hline 108 & exp Human immunodeficiency virus/ & 137,944 \\
\hline
\end{tabular}




\section{APPENDIX Systematic Review Search Strings (continued)}

Embase, 1980 to present

Search Strings Searched November 24, 2014

\begin{tabular}{|c|c|}
\hline 109 & exp B cell lymphoma/ \\
\hline 110 & hiv.ti,ab. \\
\hline 111 & hiv-1.ti,ab. \\
\hline 112 & hiv-2.ti,ab. \\
\hline 113 & human immunodeficiency virus.ti,ab. \\
\hline 114 & human immuno-deficiency virus.ti,ab. \\
\hline 115 & human immune-deficiency virus.ti,ab. \\
\hline 116 & acquired immunodeficiency syndrome.ti,ab. \\
\hline 117 & acquired immuno-deficiency syndrome.ti,ab. \\
\hline 118 & acquired immunedeficiency syndrome.ti,ab. \\
\hline 119 & acquired immune-deficiency syndrome.ti,ab. \\
\hline 120 & AIDS.mp. \\
\hline 121 & or/107-120 \\
\hline 122 & exp Human immunodeficiency virus vaccine/ \\
\hline 123 & exp antiretrovirus agent/ \\
\hline 124 & exp highly active antiretroviral therapy/ \\
\hline 125 & exp Human immunodeficiency virus fusion inhibitor/ \\
\hline 126 & exp enfuvirtide/ \\
\hline 127 & (enfuvirtide or T-20 or fuzeon).mp. \\
\hline 128 & or/122-126 \\
\hline 129 & 127 and 128 \\
\hline 130 & 4 and 121 and 129 \\
\hline 131 & exp human growth hormone/ \\
\hline 132 & exp growth hormone/ \\
\hline 133 & (human growth hormone or growth hormone or HGH).mp. \\
\hline 134 & (somatropin or somatotropin).mp. \\
\hline 135 & (genotropin or humatrope or norditropin or saizen or omni \\
\hline 136 & or/131-135 \\
\hline 137 & 4 and 136 \\
\hline 138 & 64 or 91 or 106 or 130 or 137 \\
\hline 139 & placebo:.mp. \\
\hline 140 & double-blind:.tw. \\
\hline 141 & 139 or 140 \\
\hline 142 & 138 not 141 \\
\hline 143 & limit 142 to $y r=" 2000$-Current" \\
\hline 144 & limit 143 to english \\
\hline 145 & limit 144 to (adult $<18$ to 64 years $>$ or aged $<65+$ years $>$ ) \\
\hline 146 & animal/ not (human/ and animal/) \\
\hline 147 & 145 not 146 \\
\hline
\end{tabular}

MEDLINE In-Process and Other Non-Indexed Citations and Ovid MEDLINE 1946 to Present

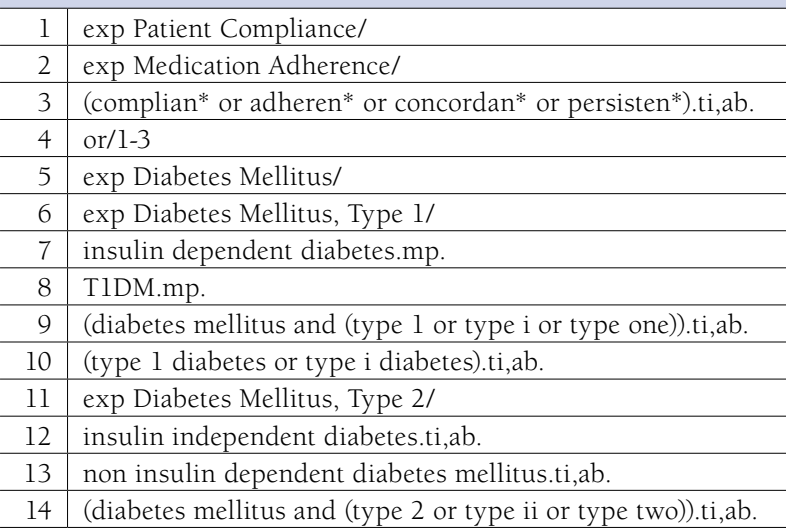

Results

23,380

272,593

71,436

4,524

74,206

230

321

15,093

110

5,301

148,631

458,143

9,980

140,768

29,942

9,074

3,304

3,931

157,228

3,374

449

9,478

53,105

79,964

3,050

2,247

80,279

1,943

12,740

324,934

144,520

370,663

11,625

9,335

8,811

3,043

$1,195,420$

3,043

Results

57,988

8,858

45,8742

486,054

330,191

64,055

20,211

2,214

15,022

30,354

91,498

127

6,862

32,253 


\section{APPENDIX Systematic Review Search Strings (continued)}

MEDLINE In-Process and Other Non-Indexed Citations and Ovid MEDLINE 1946 to Present

15 (type 2 diabetes or type ii diabetes).ti,ab.

16 NIDDM.ti,ab

\begin{tabular}{l|l}
17 & ((adult onset or adult-onset) and diabetes).mp.
\end{tabular}

18 or/5-17

19 exp Insulin/

20 insulin*ti,ab

21 human insulin.mp.

22 exp Biphasic Insulins/

23 biphasic insulin.mp.

24 bovine insulin.mp.

25 exp Insulin, Short-Acting/

26 short acting insulin.mp.

27 rapid acting insulin.mp.

28 intermediate acting insulin.mp.

29 long acting insulin.mp. or exp Insulin, Long-Acting/

30 pre-mixed insulin.mp.

31 humalog.mp. or exp Insulin Lispro/

32 exp Insulin Aspart/

33 (novolog or novorapid).mp.

34 apidra.mp.

35 regular humulin.mp.

36 novolin.mp.

37 Velosulin.mp. or exp Insulin, Regular, Pork/

38 NPH.mp. or exp Insulin, Isophane/

39 Lantus.mp.

40 levemir.mp.

41 Humulin.mp.

42 (degludec or tresiba).mp.

43 ReliOn.mp.

44 exp Glucagon-Like Peptides/

45 (glucagon like peptide or GLP).mp.

46 exenatide.mp

47 Byetta.mp

48 bydureon.mp.

49 (dulaglutide or trulicity).mp.

50 liraglutide.mp.

51 (victoza or NN2211).mp.

52 lixisenatide.mp.

53 lyxumia.mp.

54 albiglutide.mp.

55 (eperzan or tanzeum).mp.

56 pramlintide.mp

57 symlin.mp.

58 or/19-57

$59 \quad 4$ and 18 and 58

60 exp Arthritis, Rheumatoid/

61 (arthritis adj2 rheumat*).mp.

62 (felty* adj2 syndrome).mp.

63 (caplan* adj2 syndrome).mp.

64 (sjogren* adj2 syndrome).mp.

65 still* disease.mp.

66 (spondylitis adj2 ankylosing).mp.

67 or/60-66

68 exp Antirheumatic Agents/

Results

78,290

6,958

959

361,449

163,699

289,561

5,418

152

563

799

1,210

385

468

237

3,260

18

790

509

56

19

22

280

2,754

131

61

126

136

6,058

9,955

1,963

68

8

34

854

65

80

8

59

4

488

19

329,607

4,288

95,813

110,091

845

193

14,002

1,848

14,590

134,599

347,805 


\section{APPENDIX Systematic Review Search Strings (continued)}

\begin{tabular}{|c|c|c|}
\hline \multicolumn{3}{|c|}{ Search Strings Searched November 24, 2014} \\
\hline \multicolumn{2}{|r|}{ MEDLINE In-Process and Other Non-Indexed Citations and Ovid MEDLINE 1946 to Present } & Results \\
\hline 69 & (disease modifying antirheumatic drug or DMARD*).mp. & 3,024 \\
\hline 70 & (biologic response modifiers or biologics).mp. & 4,537 \\
\hline 71 & exp Interleukin 1 Receptor Antagonist Protein/ & 4,166 \\
\hline 72 & (anakinra or kineret).mp. & 940 \\
\hline 73 & (golimumab or cntol 48 or cnto 148 or simponi).mp. & 392 \\
\hline 74 & exp Immunoconjugates/ & 8,421 \\
\hline 75 & (adalimumab or humira or trudexa).mp. & 4,116 \\
\hline 76 & (abatacept or ?rencia or CTLA4 or bms 188667 or bms188667).mp. & 5,391 \\
\hline 77 & (etanercept or enbrel or tnr001 or "tnr 00l").mp. & 4,659 \\
\hline 78 & (atlizumab or tocilizumab or actemra or r 1569 or rl569).mp. & 1,094 \\
\hline 79 & ((certolizumab adj2 pegol) or cimzia or cdp870 cdp 870 or pha738144 or pha 738144).mp. & 464 \\
\hline 80 & or/68-79 & 367,102 \\
\hline 81 & 4 and 67 and 80 & 1,014 \\
\hline 82 & exp Multiple Sclerosis/ & 46,516 \\
\hline 83 & exp Encephalomyelitis, Acute Disseminated/ & 1,560 \\
\hline 84 & exp Myelitis, Transverse/ & 2,457 \\
\hline 85 & (multiple sclerosis or transverse myelitis or optic neuritis or devic or adem or neuromyelitis optica).mp. & 65,814 \\
\hline 86 & 'myelooptic neuropathy'mp. & 2 \\
\hline 87 & exp Demyelinating Diseases/ & 81,394 \\
\hline 88 & or/82-87 & 96,657 \\
\hline 89 & exp Interferon-beta/ & 7,766 \\
\hline 90 & (Interferon-beta or Interferon beta).mp. & 9,803 \\
\hline 91 & (betala interferon or betal interferon).mp. & 15 \\
\hline 92 & (avonex or rebif or betaferon or betaseron or extavia or plegridy).mp. & 492 \\
\hline 93 & glatiramer.mp. & 1,152 \\
\hline 94 & (cop-l or cop 1 or copolymer 1 or copaxone).mp. & 1,195 \\
\hline 95 & or/89-94 & 10,729 \\
\hline 96 & 4 and 88 and 95 & 324 \\
\hline 97 & exp HIV Infections/ & 246,219 \\
\hline 98 & $\operatorname{exp~HIV/~}$ & 89,074 \\
\hline 99 & exp HIV-1/ & 70,894 \\
\hline 100 & $\exp$ HIV-2/ & 3,944 \\
\hline 101 & hiv.mp. & 292,438 \\
\hline 102 & hiv-2.mp. & 5,593 \\
\hline 103 & human immunodeficiency virus.ti,ab. & 74,287 \\
\hline 104 & human immunedeficiency virus.ti,ab. & 5 \\
\hline 105 & human immuno-deficiency virus.ti,ab. & 204 \\
\hline 106 & human immune-deficiency virus.ti,ab. & 264 \\
\hline 107 & acquired immunodeficiency syndrome.ti,ab. & 15,290 \\
\hline 108 & acquired immuno-deficiency syndrome.ti,ab. & 105 \\
\hline 109 & acquired immunedeficiency syndrome.ti,ab. & 10 \\
\hline 110 & acquired immune-deficiency syndrome.ti,ab. & 5,148 \\
\hline 111 & exp Acquired Immunodeficiency Syndrome/ & 75,374 \\
\hline 112 & AIDS.mp. & 166,026 \\
\hline 113 & or/97-112 & 386,553 \\
\hline 114 & exp Anti-HIV Agents/ & 57,703 \\
\hline 115 & exp Antiviral Agents/ & 301,140 \\
\hline 116 & exp Antiretroviral Therapy, Highly Active/ & 18,633 \\
\hline 117 & (enfuvirtide or T-20 or fuzeon).mp. & 2,098 \\
\hline 118 & or/114-116 & 310,777 \\
\hline 119 & 117 and 118 & 1,491 \\
\hline 120 & 4 and 113 and 119 & 121 \\
\hline 121 & exp Human Growth Hormone/ & 11,372 \\
\hline 122 & exp Growth Hormone/ & 52,066 \\
\hline
\end{tabular}




\section{APPENDIX Systematic Review Search Strings (continued)}

Search Strings Searched November 24, 2014

MEDLINE In-Process and Other Non-Indexed Citations and Ovid MEDLINE 1946 to Present

123 (human growth hormone or growth hormone or HGH).mp.

124 (somatropin or somatotropin).mp.

125 (genotropin or humatrope or norditropin or saizen or omnitrope or nutropin or tev-tropin).mp.

126 or/121-125

$127 \quad 4$ and 126

12859 or 81 or 96 or 120 or 127

129 randomized controlled trial.pt.

130 placebo.mp

131 or/129-130

\begin{tabular}{l|l}
132 & 128 not 131
\end{tabular}

133 limit 132 to $y r=" 2000$-Current"

134 limit 133 to english

135 limit 134 to ("all adult (19 plus years)" or "adolescent (13 to 18 years)" or "young adult (19 to 24 years)" or "adult (19 to 44 years)" or "young adult and adult (19-24 and 19-44)" or "middle age (45 to 64 years)" or "middle aged (45 plus years)" or "all aged (65 and over)" or "aged ( 80 and over)")

136 animal/ not (human/ and animal/)

$137 \quad 135$ not 136

The Cochrane Library, including Cochrane Reviews, DARE, HTA, NHS EED

\begin{tabular}{l|l}
1 & exp Patient Compliance/ \\
\hline
\end{tabular}

2 exp Medication Adherence/

3 (complian* or adheren* or concordan* or persisten*).ti,ab.

\begin{tabular}{l|l}
\hline 4 & or/1-3 \\
\hline & exp 1 (ab
\end{tabular}

5 exp Diabetes Mellitus/

6 exp Diabetes Mellitus, Type 1/

7 insulin dependent diabetes.mp.

\begin{tabular}{l|l}
7 & TlDM.mp. \\
\hline
\end{tabular}

9 (diabetes mellitus and (type 1 or type i or type one)).ti,ab

10 (type 1 diabetes or type i diabetes).ti,ab.

11 exp Diabetes Mellitus, Type 2/

\begin{tabular}{l|l}
12 & insulin independent diabetes.ti,ab \\
\hline 13 & non
\end{tabular}

13 non insulin dependent diabetes mellitus.ti,ab.

14 (diabetes mellitus and (type 2 or type ii or type two)).ti,ab

15 (type 2 diabetes or type ii diabetes).ti,ab.

16 NIDDM.ti,ab.

17 ((adult onset or adult-onset) and diabetes).mp.

18 or/5-17

19 exp Insulin/

20 insulin*ti,ab

21 human insulin.mp.

22 exp Biphasic Insulins/

23 biphasic insulin.mp.

24 bovine insulin.mp.

25 exp Insulin, Short-Acting/

26 short acting insulin.mp.

27 rapid acting insulin.mp.

28 intermediate acting insulin.mp.

29 long acting insulin.mp. or exp Insulin, Long-Acting/

30 pre-mixed insulin.mp.

31 humalog.mp. or exp Insulin Lispro/

32 exp Insulin Aspart/

33 (novolog or novorapid).mp. [mp =ti, ab, tx, kw, ct, hw]

34 apidra.mp.

35 regular humulin.mp

36 novolin.mp. 


\section{APPENDIX Systematic Review Search Strings (continued)}

Search Strings Searched November 24, 2014

The Cochrane Library, including Cochrane Reviews, DARE, HTA, NHS EED

37 Velosulin.mp. or exp Insulin, Regular, Pork/

38 NPH.mp. or exp Insulin, Isophane/

39 Lantus.mp.

40 levemir.mp

41 Humulin.mp

42 (degludec or tresiba).mp. [mp=ti, ab, tx, kw, ct, hw]

43 ReliOn.mp.

44 exp Glucagon-Like Peptides/

45 (glucagon like peptide or GLP).mp.

46 exenatide.mp

47 Byetta.mp.

48 bydureon.mp.

49 (dulaglutide or trulicity).mp. [mp=ti, ab, tx, kw, ct, hw]

50 liraglutide.mp.

51 (victoza or NN2211).mp

52 lixisenatide.mp.

53 lyxumia.mp.

54 albiglutide.mp.

55 (eperzan or tanzeum).mp.

56 pramlintide.mp.

57 symlin.mp

58 or/19-57

$59 \quad 4$ and 18 and 58

60 exp Arthritis, Rheumatoid/

61 (arthritis adj2 rheumat*).mp.

62 (felty* adj2 syndrome).mp.

63 (caplan* adj2 syndrome).mp.

64 (sjogren* adj2 syndrome).mp.

65 still* disease.mp.

66 (spondylitis adj2 ankylosing).mp.

67 or/60-66

68 exp Antirheumatic Agents/

69 (disease modifying antirheumatic drug or DMARD*).mp.

70 (biologic response modifiers or biologics).mp.

71 exp Interleukin 1 Receptor Antagonist Protein/

72 (anakinra or kineret).mp.

73 (golimumab or cntol48 or cnto 148 or simponi).mp.

74 exp Immunoconjugates/

75 (adalimumab or humira or trudexa).mp.

76 (abatacept or ?rencia or CTLA4 or bms 188667 or bmsl88667).mp.

77 (etanercept or enbrel or tnr001 or "tnr 001").mp.

78 (atlizumab or tocilizumab or actemra or r 1569 or r1569).mp.

79 ((certolizumab adj2 pegol) or cimzia or cdp870 cdp 870 or pha738144 or pha 738144).mp.

80 or/68-79

$81 \quad 4$ and 67 and 80

82 exp Multiple Sclerosis/

83 exp Encephalomyelitis, Acute Disseminated/

84 exp Myelitis, Transverse/

85 (multiple sclerosis or transverse myelitis or optic neuritis or devic or adem or neuromyelitis optica).mp.

86 'myelooptic neuropathy'.mp.

87 exp Demyelinating Diseases/

88 or/82-87

89 exp Interferon-beta/

90 (Interferon-beta or Interferon beta).mp.

Results

187

73

2

1

9 


\section{APPENDIX Systematic Review Search Strings (continued)}

Search Strings Searched November 24, 2014

The Cochrane Library, including Cochrane Reviews, DARE, HTA, NHS EED

91 (betala interferon or betal interferon).mp.

92 (avonex or rebif or betaferon or betaseron or extavia or plegridy).mp.

93 glatiramer.mp.

94 (cop-1 or cop 1 or copolymer 1 or copaxone).mp.

95 or/89-94

$96 \quad 4$ and 88 and 95

97 exp HIV Infections/

98 exp HIV/

99 exp HIV-1/

100 exp HIV-2/

101 hiv.mp.

102 hiv-2.mp.

103 human immunodeficiency virus.ti,ab.

104 human immunedeficiency virus.ti,ab.

105 human immuno-deficiency virus.ti,ab.

106 human immune-deficiency virus.ti,ab

107 acquired immunodeficiency syndrome.ti,ab.

108 acquired immuno-deficiency syndrome.ti,ab.

109 acquired immunedeficiency syndrome.ti,ab.

110 acquired immune-deficiency syndrome.ti,ab

111 exp Acquired Immunodeficiency Syndrome/

112 AIDS.mp.

113 or/97-112

114 exp Anti-HIV Agents/

115 exp Antiviral Agents/

116 exp Antiretroviral Therapy, Highly Active/

117 (enfuvirtide or T-20 or fuzeon).mp.

118 or/114-116

\begin{tabular}{l|l}
118 & 117 and 118
\end{tabular}

$120 \quad 4$ and 113 and 119

121 exp Human Growth Hormone/

122 exp Growth Hormone/

123 (human growth hormone or growth hormone or HGH).mp

124 (somatropin or somatotropin).mp.

125 (genotropin or humatrope or norditropin or saizen or omnitrope or nutropin or tev-tropin).mp.

126 or/121-125

$127 \quad 4$ and 126

12859 or 81 or 96 or 120 or 127

\section{Embase 1980 to 2015 Week 26}

Update Search Strings Searched June 29, 2015

Results

0

23

41

10

129

3

682

130

83

3

2,153

35

99

0

0

61

1,609

3,021

254

744

109

25

794

14

0

37

46

188

28

16

189

20

Results

110,331

8,768

599,798

652,123

646,611

83,898

22,256

4,650

20,862

43,673

159,092

134

15,975

49,269 


\section{APPENDIX Systematic Review Search Strings (continued)}

Embase 1980 to 2015 Week 26

Update Search Strings Searched June 29, 2015

15 (type 2 diabetes or type ii diabetes).ti,ab.

16 NIDDM.ti,ab.

17 ((adult onset or adult-onset) and diabetes).mp.

18 or/5-17

19 exp insulin/

20 insulin*.ti,ab.

21 exp human insulin/

22 exp biphasic insulin/

23 exp bovine insulin/

24 human insulin.mp.

25 biphasic insulin.mp.

26 bovine insulin.mp.

27 exp short acting insulin/

28 short acting insulin.mp.

29 rapid acting insulin.mp.

30 intermediate acting insulin.mp.

31 long acting insulin.mp. or exp long acting insulin/

32 pre-mixed insulin.mp.

33 humalog.mp. or exp insulin lispro/

34 exp insulin aspart/

35 (novolog or novorapid).mp. [mp = title, abstract, heading word, drug trade name, original title, device manufacturer,

drug manufacturer, device trade name, keyword]

36 Apidra.mp. or exp insulin glulisine/

37 Regular humulin.mp

38 novolin.mp.

39 Velosulin.mp. or exp neutral insulin/

40 NPH.mp. or exp isophane insulin/

41 Lantus.mp. or exp insulin glargine/

42 Levemir.mp. or exp insulin detemir/

43 Humulin.mp.

44 exp insulin degludec/ or degludec.mp.

45 tresiba.mp.

46 ReliOn.mp.

47 or/19-46

$48 \quad 4$ and 18 and 47

49 placebo:.mp.

50 double-blind:.tw.

\begin{tabular}{l|l|l}
51 & 49 or 50 \\
\hline 52 & 48 not 51
\end{tabular}

$52 \quad 48$ not 51

53 limit 52 to $\mathrm{dd}=20141124-20150629$

54 ("Nov* 2014" or "Dec* 2014").dp.

55 "2015".dp.

5654 or 55

$57 \quad 52$ and 56

5853 or 57

59 limit 58 to (english and (adult $<18$ to 64 years $>$ or aged $<65+$ years $>$ ))

60 animal/ not (human/ and animal/)

6159 not 60

Ovid MEDLINE In-Process \& Other Non-Indexed Citations and Ovid MEDLINE 1946 to Present

\begin{tabular}{r|l}
\hline 1 & exp Patient Compliance/ \\
\hline 2 & exp Medication Adherence/ \\
\hline 3 & (complian* or adheren* or concordan* or persisten*).ti,ab \\
\hline 4 & or/l-3 \\
\hline 5 & exp Diabetes Mellitus/
\end{tabular}

Results

118,106

7,772

1,195

663,386

253,199

354,613

4,177

596

720

10,490

1,034

1,280

637

1,139

827

306

2,050

59

4,270

3,670

1,134

1,167

552

3,142

8,167

6,499

2,572

1,645

551

41

16

425,424

8,348

340,182

151,709

388,027

7,760

441

41,333

59,202

100,535

57

450

169

$1,251,256$

169

Results

57,649

9,326

465,434

492,430

330,360 


\section{APPENDIX Systematic Review Search Strings (continued)}

Update Search Strings Searched June 29, 2015

Ovid MEDLINE In-Process \& Other Non-Indexed Citations and Ovid MEDLINE 1946 to Present

6 exp Diabetes Mellitus, Type 1/

7 insulin dependent diabetes.mp.

8 TlDM.mp.

9 (diabetes mellitus and (type 1 or type i or type one)).ti,ab

10 (type 1 diabetes or type i diabetes).ti,ab.

11 exp Diabetes Mellitus, Type 2/

12 insulin independent diabetes.ti,ab

13 non insulin dependent diabetes mellitus.ti,ab

14 (diabetes mellitus and (type 2 or type ii or type two)).ti,ab.

15 (type 2 diabetes or type ii diabetes).ti,ab.

16 NIDDM.ti,ab.

17 ((adult onset or adult-onset) and diabetes).mp.

18 or/5-17

19 exp Insulin/

20 insulin*.ti,ab

21 human insulin.mp.

22 exp Biphasic Insulins/

23 biphasic insulin.mp.

24 bovine insulin.mp.

25 exp Insulin, Short-Acting/

26 short acting insulin.mp.

27 rapid acting insulin.mp.

28 intermediate acting insulin.mp.

29 long acting insulin.mp. or exp Insulin, Long-Acting/

30 pre-mixed insulin.mp.

31 humalog.mp. or exp Insulin Lispro/

32 exp Insulin Aspart/

33 (novolog or novorapid).mp. [mp = title, abstract, original title, name of substance word, subject heading word, keyword heading word, protocol supplementary concept word, rare disease supplementary concept word, unique identifier]

34 apidra.mp.

35 regular humulin.mp

36 novolin.mp.

37 Velosulin.mp. or exp Insulin, Regular, Pork/

38 NPH.mp. or exp Insulin, Isophane/

39 Lantus.mp.

40 levemir.mp.

41 Humulin.mp.

42 (degludec or tresiba).mp. [mp =title, abstract, original title, name of substance word, subject heading word, keyword heading word, protocol supplementary concept word, rare disease supplementary concept word, unique identifier]

43 ReliOn.mp.

44 or/19-43

$45 \quad 4$ and 18 and 44

46 randomized controlled trial.pt.

47 placebo.mp.

48 46 or 47

\begin{tabular}{l|l}
49 & 45 not 48 \\
\hline 50 & limit 49 to
\end{tabular}

50 limit 49 to ed $=20141124-20150629$

51 ("2014 Nov*" or "2014 Dec*").dp.

52 2015*.dp.

5351 or 52

$54 \quad 49$ and 53

5550 or 54

56 limit 55 to (("all adult (19 plus years)" or "adolescent (13 to 18 years)" or "young adult (19 to 24 years)" or "adult (19 to 44 years)" or "young adult and adult (19-24 and 19-44)" or "middle age (45 to 64 years)" or "middle aged (45 plus years)" or "all aged (65 and over)" or "aged ( 80 and over)") and english)

Results

63,710

19,960

2,351

15,203

30,768

92,365

128

6,718

33,755

80,905

6,820

943

364,040

161,622

289,790

5,407

153

\section{6}

807

1,210

384

476

238

3,290

21

796

513

56

20

1

21

277

2,751

129

61

125

167

323,807

4,276

398,215

169,137

475,470

3,809

111

138,555

505,791

644,346

99

175 


\section{APPENDIX Systematic Review Search Strings (continued)}

Update Search Strings Searched June 29, 2015

Ovid MEDLINE In-Process \& Other Non-Indexed Citations and Ovid MEDLINE 1946 to Present

57 animal/ not (human/ and animal/)

$58 \quad 56$ not 57

CDSR, DARE, CLHTA, CLEED

1 exp Patient Compliance/

2 exp Medication Adherence/

3 (complian* or adheren* or concordan* or persisten*).ti,ab.

4 or/1-3

exp Diabetes Mellitus/

exp Diabetes Mellitus, Type 1/

7 insulin dependent diabetes.mp.

8 TlDM.mp.

9 (diabetes mellitus and (type 1 or type i or type one)).ti,ab.

10 (type 1 diabetes or type i diabetes).ti,ab

11 exp Diabetes Mellitus, Type 2/

12 insulin independent diabetes.ti,ab.

13 non insulin dependent diabetes mellitus.ti,ab.

14 (diabetes mellitus and (type 2 or type ii or type two)).ti,ab.

15 (type 2 diabetes or type ii diabetes).ti,ab.

16 NIDDM.ti,ab.

17 ((adult onset or adult-onset) and diabetes).mp

18 or $/ 5-17$

19 exp Insulin/

20 insulin*.ti,ab.

21 human insulin.mp.

22 exp Biphasic Insulins/

23 biphasic insulin.mp.

24 bovine insulin.mp.

25 exp Insulin, Short-Acting/

26 short acting insulin.mp.

27 rapid acting insulin.mp.

28 intermediate acting insulin.mp.

29 long acting insulin.mp. or exp Insulin, Long-Acting/

30 pre-mixed insulin.mp.

31 humalog.mp. or exp Insulin Lispro/

32 exp Insulin Aspart/

33 (novolog or novorapid).mp. [mp = ti, ab, tx, kw, ct, hw]

34 apidra.mp.

35 regular humulin.mp.

36 novolin.mp

37 Velosulin.mp. or exp Insulin, Regular, Pork/

38 NPH.mp. or exp Insulin, Isophane/

39 Lantus.mp.

40 levemir.mp.

41 Humulin.mp.

42 (degludec or tresiba).mp. [mp =ti, ab, tx, kw, ct, hw]

43 ReliOn.mp.

44 or/19-43

$45 \quad 4$ and 18 and 44

46 limit 45 to yr= "2014 -Current" [Limit not valid in DARE; records were retained] 